\title{
An Introduction to Geophysical and Geochemical Methods in Digital Geoarchaeology
}

\author{
Apostolos Sarris, Tuna Kalayci, Ian Moffat, \\ and Meropi Manataki
}

\begin{abstract}
Archaeological geophysics is a range of techniques for the minimally invasive, remote investigation of the physical parameters of the nearsurface environment. This suite of methods is complementary to archaeological survey or excavation as it can provide information about the stratigraphy of the survey area, locate anthropogenic traces of the past, document their spatial dimensions and - under ideal conditions - explore the physical properties of subsurface materials. Both material culture items such as a building foundations and indirect indications of anthropogenic activity such as subsurface disturbance or evidence of burning are excellent direct targets for geophysical investigations since they can be differentiated on the basis of their material properties from the wider soil context. In addition to directly locating archaeological material, geophysical techniques can make an important contribution to geoarchaeological investigations by elucidating the site stratigraphy and mapping its lateral geometry. In some cases, such as when locating prehistoric material buried offshore or within open Palaeolithic sites, the reconstruction of past landscapes may make a more important contribution to archaeological investigations than the direct geophysical detection of archaeological materials.

Different material culture items have characteristic physical properties (such as electrical resistance or conductivity, magnetic susceptibility) and so require different instrumentation for effective detection. The main techniques for archaeological prospection include magnetometer, resistance meter, magnetic susceptibility meter, ground-penetrating radar and electromagnetic induction meter. Apart from that, seismic methods (reflection and refraction seismics), gamma spectroscopy and gravity techniques are also used in certain circumstances.
\end{abstract}

A. Sarris $(\bowtie) \cdot$ T. Kalayci $\bullet$ I. Moffat • M. Manataki GeoSat ReSeArch Lab, Foundation for Research and Technology, Hellas (F.O.R.T.H.), Rethymno, Crete, Greece

e-mail: asaris@ret.forthnet.gr 
Unfortunately, there is no standard approach for the application of one specific geophysical method for all archaeological materials in all geological environments. The success of geophysical prospection techniques depends on a combination of soil and sediment characteristics as well as depth below surface and preservation of archaeological findings. In order to achieve the most reliable results and enhance the chance of detecting archaeological material, an integrated, multi-method approach is suggested.

In addition to field surveying, the effective processing of measured geophysical data is a crucial part of the interpretation process. Data processing aims to enhance signals of interest in order to better delineate archaeological and geological features. It helps to produce more interpretable results and therefore facilitates and fosters collaboration between geophysicists and archaeologists.

\section{Keywords}

Geophysics • Landscape archaeology • Palaeolandscape reconstruction • Soil stratigraphy

\subsection{Introduction}

Geophysical methods are an important component of geoarchaeological investigations due to their ability to non-invasively image the subsurface of an archaeological landscape. New developments in multi-sensor and positioning technology have facilitated the use of these methods over large areas, allowing archaeological questions to be addressed on a landscape scale. They are particularly useful in geoarchaeological investigations for defining site stratigraphy, mapping site disturbance and reconstructing palaeolandscapes.

Geophysical methods also make a significant contribution to archaeological investigations beyond geoarchaeology. Excellent detailed introductions to the application of specific geophysical techniques to archaeology in general are available for ground-penetrating radar (Manataki et al. 2015; Conyers 2013, 2015b), magnetometry (Armstrong and Kalayci 2015; Aspinall et al. 2008), resistivity (Schmidt 2013) and electromagnetic techniques (Simon and Moffat 2015).

\subsection{An Overview of Geophysical Methods}

\subsubsection{Ground-Penetrating Radar}

Ground-penetrating radar (GPR) is a widely used technique in geoarchaeology, which allows the detection of features in the subsurface that cause a change in the propagation of electromagnetic energy. A typical GPR includes a transmitting antenna $(\mathrm{Tx})$ and a receiver antenna $(\mathrm{Rx})$. The Tx transmits electromagnetic waves with a fixed frequency into the subsurface. The $\mathrm{Rx}$ receives the portion of the energy, which is reflected by variations in material properties of the subsurface and registers the amplitude of this response for mapping purposes (Fig. 14.1).

Electromagnetic wave propagation is complex as it includes reflections, refractions and diffractions caused by changes in relative dielectric permittivity $(\varepsilon)$ and/or conductivity $(\sigma)$. Variations in these values reflect geological and/or geomorphologic features (e.g. changes in 


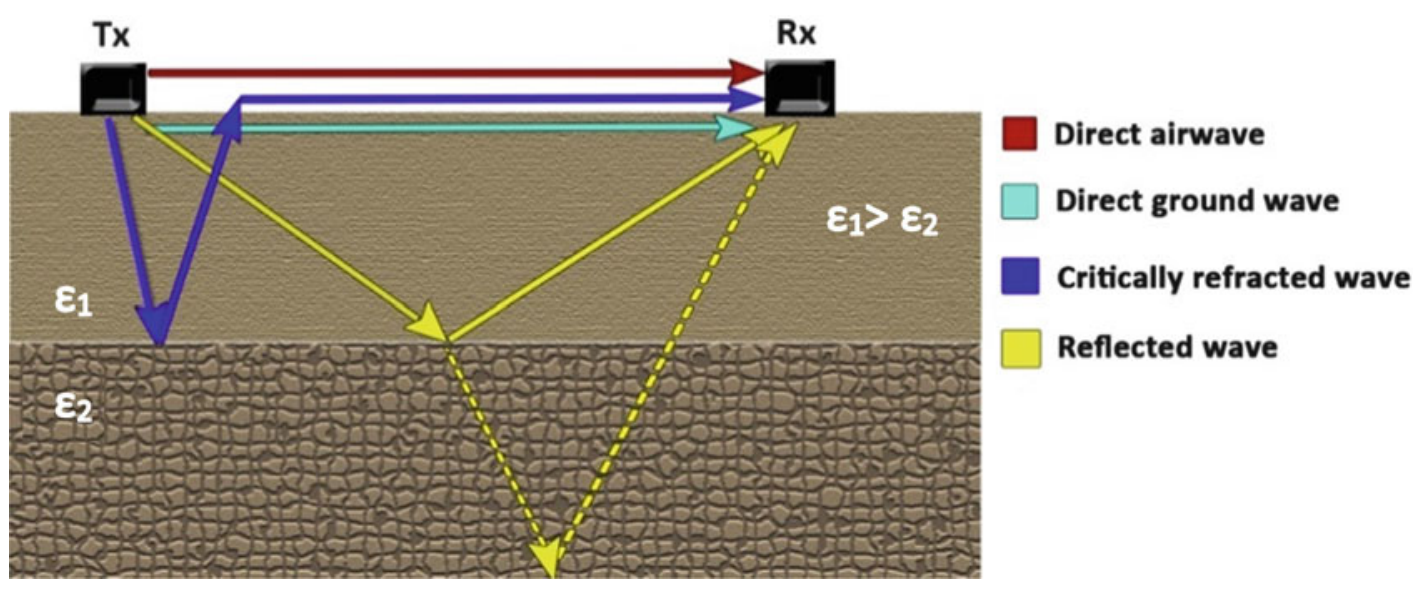

Fig. 14.1 Signal paths between the transmitter (Tx) and the receiver $(\mathrm{Rx})$ for two layers with different electrical properties ( $\varepsilon$ stands for the dielectric permittivity). The

lithology, faults, strike and dip of beds, cavities, bedding features, loose sediments vs. bedrock etc.), changes in hydrological conditions (degree of fluid saturation and water chemistry) or the presence of archaeological materials. GPR can be deployed with a variety of antenna frequencies allowing features on a wide range of scales to be imaged. In general, antennas with a frequency range of approximately $200-500 \mathrm{MHz}$ are appropriate for most archaeological studies as they provide a depth of investigation up to about $3 \mathrm{~m}$ and an acceptable resolution (Fig. 14.2a) (Jol 1995; Conyers 2015a, b, pp. 14-15). Lowerfrequency antennas can be used for deeper investigations (such as the location of geomorphic features), and higher frequency antennas are suitable for shallower, higher resolution surveys such as investigation of mortar thickness. Recent developments in GPR technology include multichannel systems (Fig. 14.2b) coupled with GPS navigation systems for fast surveys, ultra-wideband antennas (Trinks et al. 2010) and steppedfrequency antennas (Linford et al. 2010). Dronemounted GPR systems are also expected to become available within the coming years (Merz et al. 2015).

Usually, GPR surveys are undertaken on a grid of regularly spaced parallel lines, which are commonly post-processed together into a $3 \mathrm{D}$ volume. Radargrams represent the amplitude dashed yellow line indicates that part of the signal's energy was refracted and then reflected (Annan 2009)

of the reflected signals as a function of the time taken for the electromagnetic wave to travel from the Tx to the Rx via the subsurface. When the velocity of propagation of the electromagnetic radiation within the ground can be estimated, it is possible to convert the time of arrival to a depth estimate. GPR data can be viewed as 1D soundings (traces), 2D profiles (radargrams), amplitude 'slices' through the 3D volume, 3D cubes or $3 \mathrm{D}$ representation of the signal amplitude. In general, amplitude slicing is more effective for mapping archaeological features with obvious linear geometry and a high amplitude response than for stratigraphic features which are often more geometrically complex. For the investigation of geoarchaeological research questions, the combined analysis of individual traces, 2D profiles and slice maps is most likely to be more effective than the exclusive use of slice maps (Conyers 2015a, b).

GPR applications in geoarchaeology range from determination of the depth to bedrock, mapping of palaeolandscape features (such as channels and shorelines, Fig. 14.3), locating of anthropogenic earthwork features like canals or moats and identification of soil disturbance due to habitation (Fig. 14.4). In addition, GPR allows mapping unmarked graves, which often can be identified through soil anomalies caused by excavation of tombs. Unfortunately, the high 
a

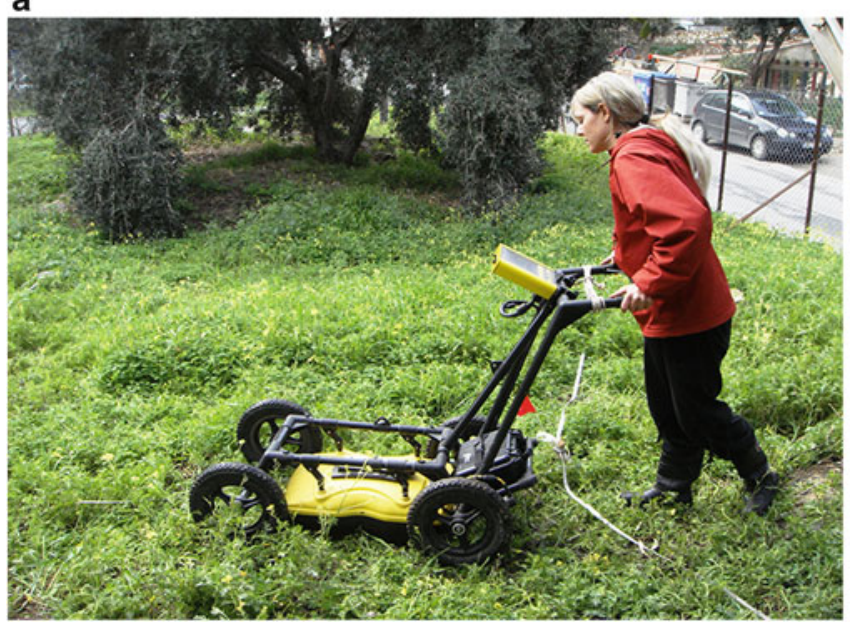

b

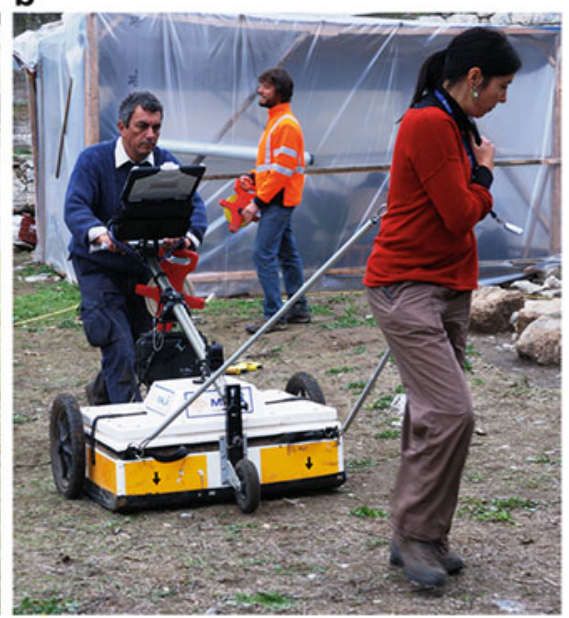

Fig. 14.2 (a) Noggin Plus (Sensors \& Software Ltd.) $250 \mathrm{MHz}$ GPR system in a survey at the ancient theatre of Chersonessos in Crete. (b) MALA MIRA multi- antenna GPR configuration with eight $400 \mathrm{MHz}$ antenna applied in a survey at Feres (Velestino), Central Greece

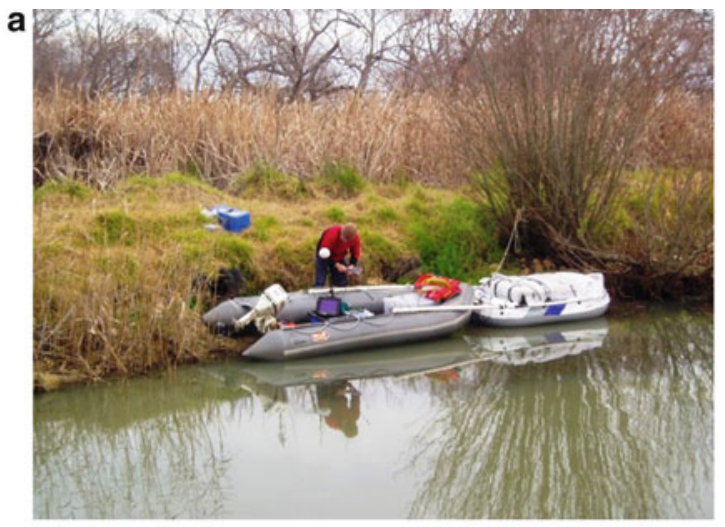

b。

DISTANCE [METER]

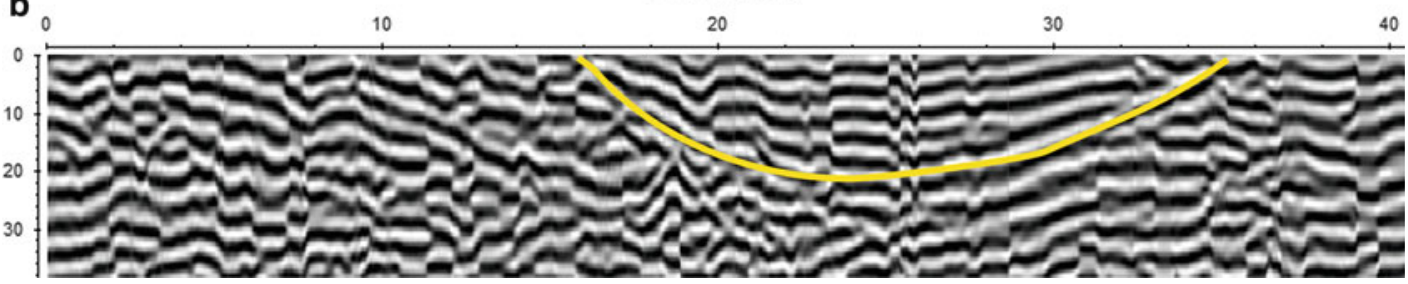

Fig. 14.3 (a) Mala X3M 100 Mhz GPR system being used for mapping sedimentary environments within a lake. Lake Alexandrina, South Australia. (b) A

attenuation of radar energy in saltwater precludes the application of GPR in marine surveys, but it is suitable for use in limnic environments (Fig. 14.3). palaeochannel (see the yellow line) imaged in a 2D profile using a Mala X3M $250 \mathrm{MHz}$ ground-penetrating radar from the Umbum Creek, Central Australia

A major advantage of GPR for geoarchaeological studies is that it can image sedimentary structures, such as cross bedding. Thus, it is an effective technique to be applied in areas 
a

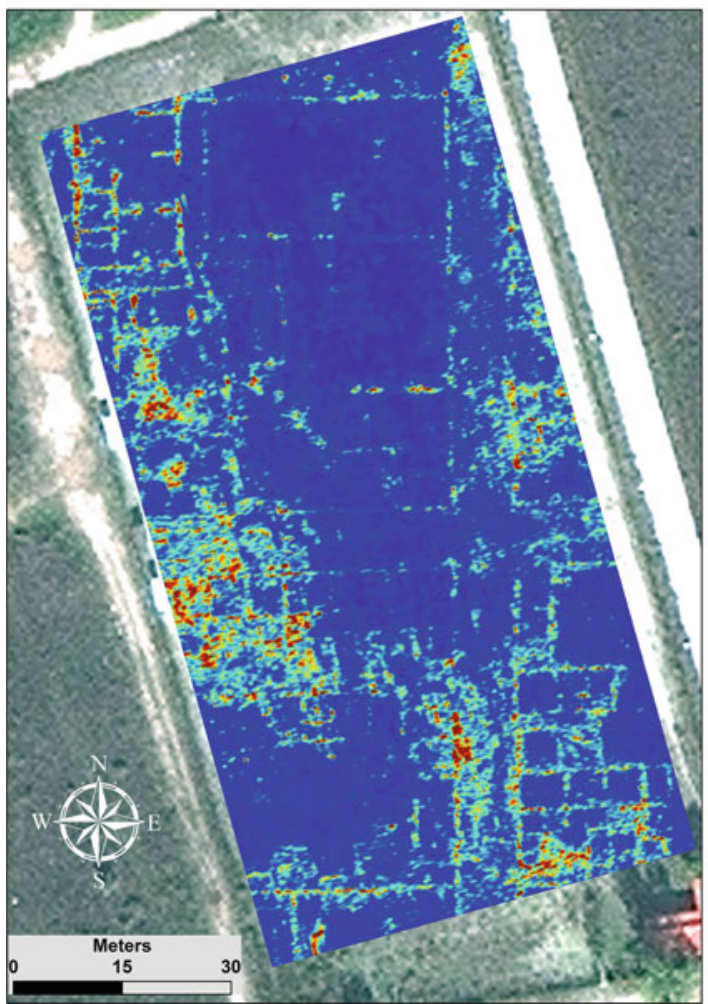

Fig. 14.4 (a) Results of GPR slices at about $60-70 \mathrm{~cm}$ below the surface resulting from Noggin Plus and MALA. (b) GPR systems from Demetrias archaeological site,

characterized by changes in depositional facies that are not accompanied by lithological changes. Moreover, as the GPR antenna can be moved continuously during data acquisition, the method allows faster data acquisition and higher survey speed compared to methods such as resistivity tomography (see below) that require stakes to be inserted in the ground. GPR also benefits from the shielding commonly placed around antennas, which reduces the interference from features on the surface (particularly metal) as opposed to other methods, such as electromagnetic induction or magnetometry, making it suitable for use in urban settings (Sarris and Papadopoulos 2012; Papadopoulos et al. 2009). b

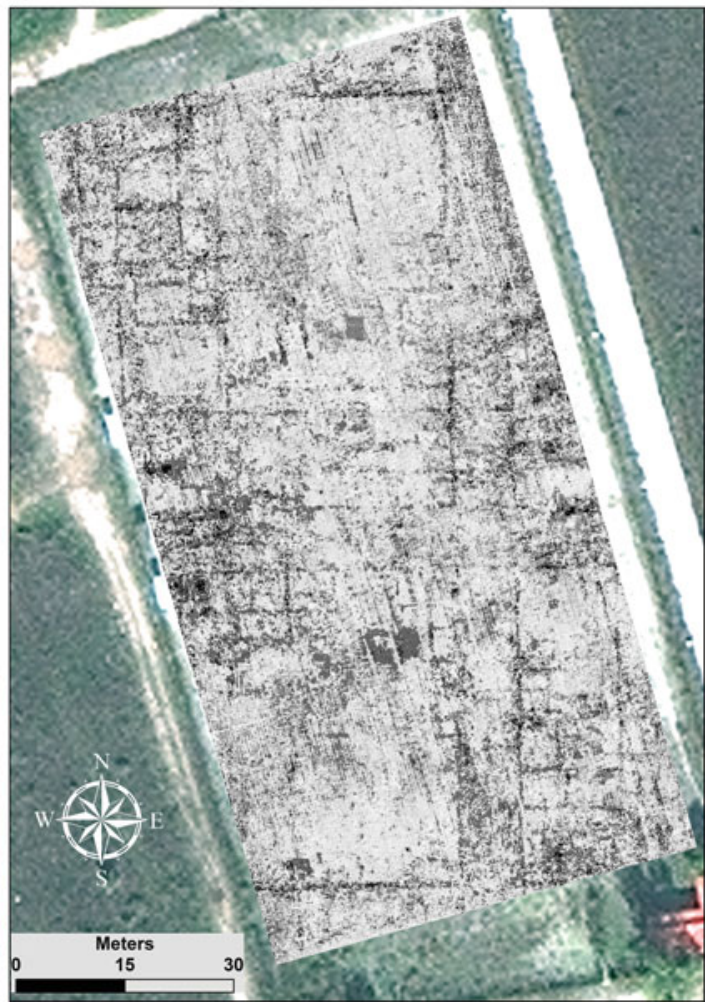

Central Greece. Measurements were taken along transects $0.5 \mathrm{~m}$ apart

\subsubsection{Electromagnetic Induction Methods}

Electromagnetic induction (EMI) can be used to calculate the apparent conductivity and magnetic susceptibility of the subsurface. In the most common type of EM instruments, a transmitter coil generates a primary electromagnetic field for a given frequency ( 8-90 kHz) (Fig. 14.5). The interaction of the field with subsurface elements generates an electrical current. This electrical current, in return, generates a secondary electromagnetic field which is sensed by a receiver coil in the instrument alongside the primary field. The magnitude of secondary field is divided into two 
Fig. 14.5 Diagrammatic representation of the principle of operation of the electromagnetic induction methods

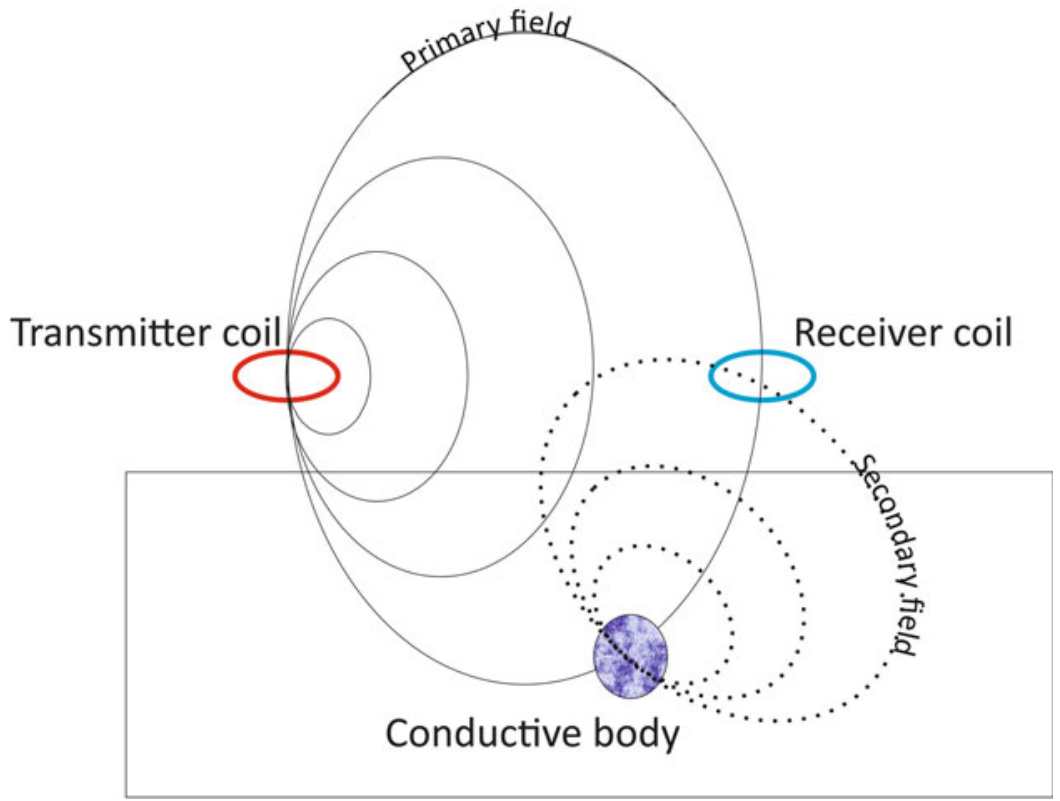

orthogonal components: the quadrature and the in-phase. The quadrature provides information on apparent conductivity (in $\mathrm{mS} / \mathrm{m}$ ), and the in-phase is related to the magnetic susceptibility (emu) of materials. The depth of investigation is mainly controlled by the separation between the transmitter and the receiver coils (Fig. 14.6; Simon et al. 2015a, b).

EM requires no direct contact with the ground surface allowing large areas to be surveyed relatively quickly (Fig. 14.6 and 14.7). Conductivity can be a good measure of changes in rock and soil units, because it is influenced by composition, the porosity, degree of water saturation and fluid chemistry. Magnetic susceptibility may provide information about erosion, pedogenesis and anthropogenic burning as all of these processes may form or concentrate magnetic minerals (French 2003).

Another subfield of the use of electromagnetic induction in geoarchaeology is the specific investigation of magnetic susceptibility by dedicated instruments. Corresponding instruments are more sensitive to changes in magnetic susceptibility than general-purpose electromagnetic induction instruments and can be used to survey on the surface, on archaeological sites and excavations and even down in drill holes (Dalan and Banerjee 1998). However, such applications are often complemented by more detailed magnetic measurements (Dalan 2007), as explained in the section on magnetic methods below.

\subsubsection{Electrical Resistance Techniques}

Electrical resistivity investigations work by measuring either the self-potential (passive) or the direct current resistivity or induced polarization (active) of the subsurface. The resistivity of geological and archaeological materials is controlled by their physical properties as well as their water chemistry and degree of saturation (Hecht and Fassbinder 2006).

Electrical resistivity surveys are undertaken between probes of a known separation. The larger the separation between the electrodes, the greater the penetration depth and the smaller the resolution. Various electrode configurations can be used, including the Twin, Wenner, Square, pole-dipole, dipole-dipole and Schlumberger arrays (Loke 2000; Fig. 14.8). Each configuration provides particular advantages for specific 
a
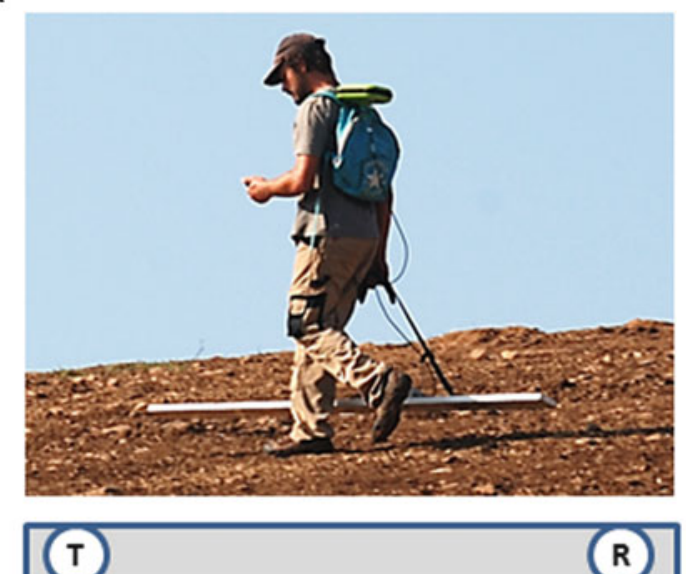

\section{GEM2 - Geophex}

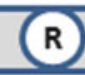

b

CMD Mini explorer - GF Instruments

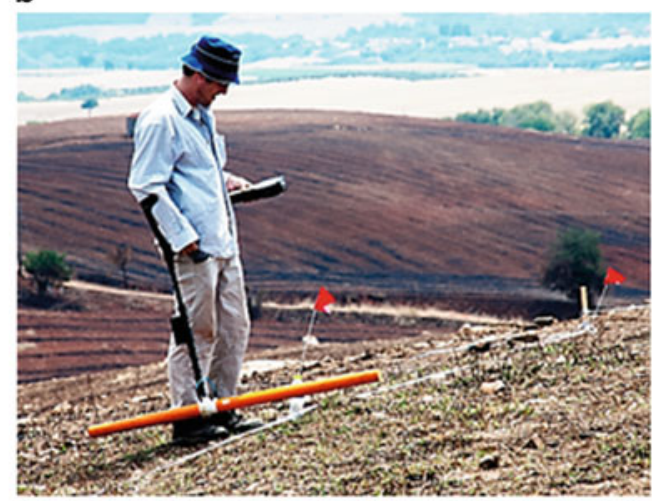

(T)

( $R_{2}$

R3)

\begin{tabular}{|c|c|l|l|l|l|l|}
\hline & \multicolumn{3}{|c|}{ GEM2 } & \multicolumn{4}{c|}{ CMD Mini Explorer } \\
\hline & Configuration & Depth & Configuration & Depth $\left(\mathrm{T}_{1}\right)$ & Depth $\left(\mathrm{T}_{2}\right)$ & Depth $\left(\mathrm{T}_{3}\right)$ \\
\hline \multirow{2}{*}{$\begin{array}{c}\text { Electrical } \\
\text { Conductivity }\end{array}$} & $\mathrm{HCP}$ & $2.5 \mathrm{~m}$ & HCP & $0.5 \mathrm{~m}$ & $1 \mathrm{~m}$ & $2 \mathrm{~m}$ \\
\cline { 2 - 7 } & & & VCP & $0.3 \mathrm{~m}$ & $0.7 \mathrm{~m}$ & $1.3 \mathrm{~m}$ \\
\hline $\begin{array}{c}\text { Magnetic } \\
\text { susceptibility }\end{array}$ & $\mathrm{HCP}$ & $1.7 \mathrm{~m}$ & $\mathrm{HCP}$ & $0.2 \mathrm{~m}$ & $0.5 \mathrm{~m}$ & $1 \mathrm{~m}$ \\
\cline { 2 - 7 } & & & VCP & $0.3 \mathrm{~m}$ & $0.7 \mathrm{~m}$ & $1.3 \mathrm{~m}$ \\
\hline
\end{tabular}

Fig. 14.6 GEM2 Geophex (a) and CMD Mini ExplorerCF Instruments (b) configurations and coil arrays for the investigation of the soil conductivity and soil magnetic susceptibility with respect to the coil separation and orientation of coils (horizontal HCP and vertical VCP)

a number of parallel ERT transects, it is possible to generate 3D volumetric images of the resistivity. Resistivity, especially when used in the ERT configuration, together with seismic techniques, is excellent for imaging changes in lithology and geology (Laigre et al. 2012; Scapozza and Laigre 2014). ERT is also valuable when either deep depositional targets (e.g. ancient ports covered by alluvial deposits, ditches and palaeochannels) or offshore archaeological features are the target of investigations (Sarris et al. 2014; Tonkov 2014; Simyrdanis et al. 2015).

\subsubsection{Magnetic Methods}

Magnetic prospection (or magnetometry) works by measuring disturbances to the earth's magnetic field caused by the presence of iron minerals. Magnetization of bodies consists of two components, namely, the induced and the remanent magnetization. While the former is 

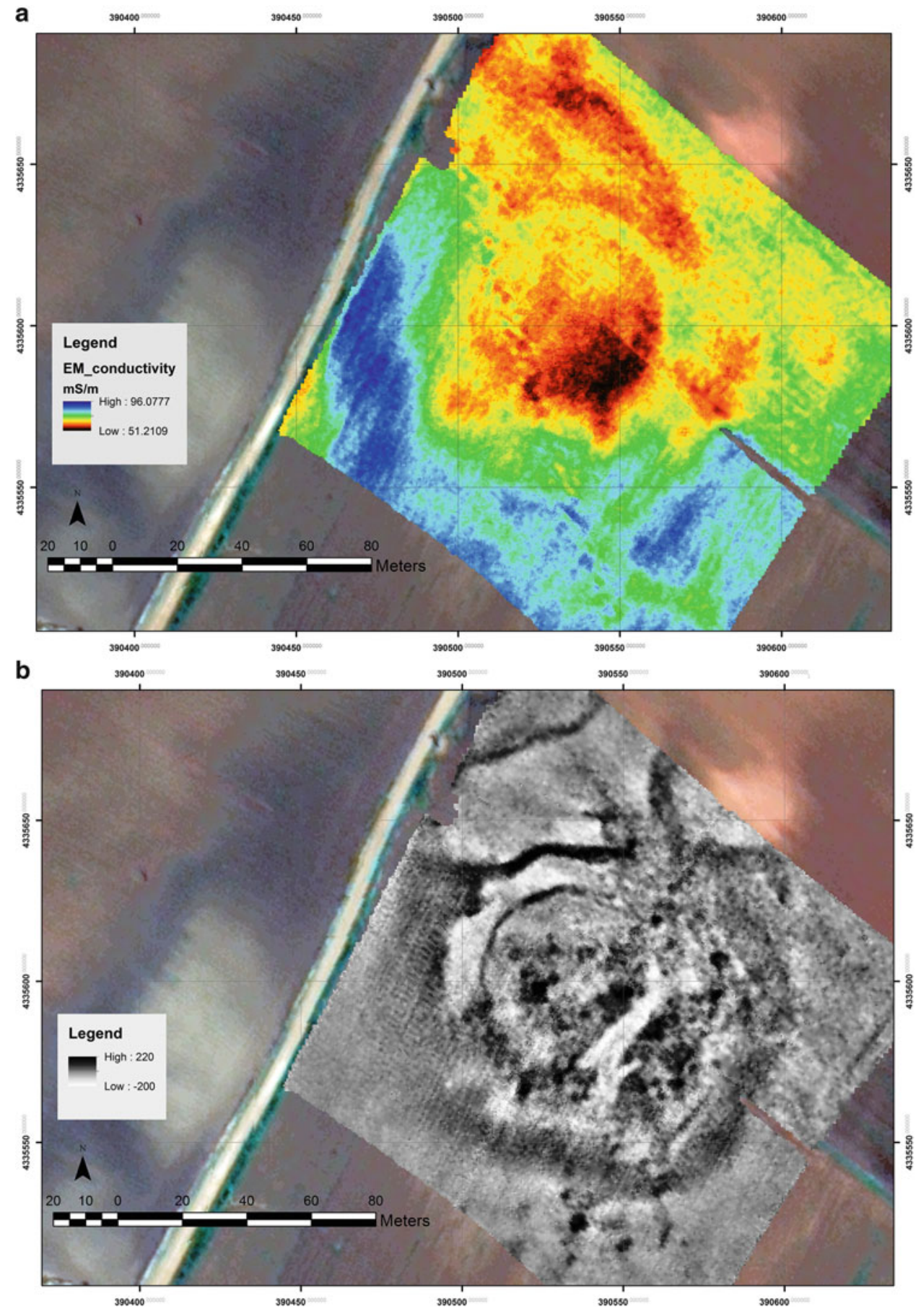

Fig. 14.7 Indicative results from the EMI survey (GEM2) at the Neolithic site of Almyros 2 at Thessaly, Greece representing the soil conductivity (a), which suggests a higher conductivity to the southern side of the tell (indicative of the flooding zone) and the magnetic susceptibility (b) that outline the surrounding ditches and some of the details of the structural remains of the core of the settlement (Sarris et al. 2015a) 

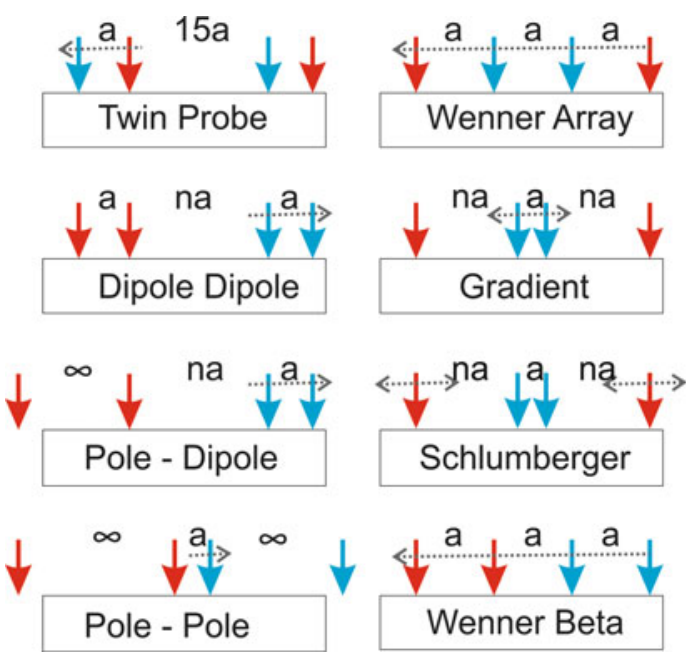

Fig. 14.8 Indicative electrode configurations used in a soil resistance survey. Blue arrows represent potential electrodes, and red arrows represent current electrodes. The distance between them varies according to the electrode array. In the mapping mode, either all or some of the electrodes move within the area of interest

created by the modern magnetic field, the latter is a result from previous magnetic fields. Magnetic susceptibility is an additional important parameter, which measures the degree to which a material becomes magnetized when an external magnetic field is applied. Magnetic prospection depends on several parameters, such as the degree and orientation of induced and remanent magnetization of bodies, their magnetic susceptibility, their volume (or mass) and their distance from the sensor.

Magnetic measurements can be collected with single or multiple sensors configured to measure usually either the total magnetic field intensity or the total or vertical magnetic gradient (gradiometer mode). Recent equipment developments have introduced multiple sensor array carts to archaeology which, when combined with high-quality positioning and navigation systems, facilitate extremely high-sample density measurements over large areas extremely quickly (Fig. 14.10).

Contrary to its widespread application for archaeological prospection, field magnetometry plays a rather little role within geoarchaeological investigations. This is mainly because it is rather suited for the direct detection of ferrous or burnt materials than for understanding the stratigraphic matrix that contains archaeological material. One promising application, though, is mapping the extent of pedogenic soil minerals, which is more effective using single sensor equipment instead of gradiometry equipment.

In contrast, laboratory magnetic measurements are very useful for understanding the depositional conditions at archaeological sites (Dalan and Banerjee 1998). Magnetic susceptibility, particularly the frequency dependant component, is increased by archaeological occupation both through heating and the addition of organic material to the soil. The surface distribution of magnetic susceptibility values provides a proxy for the spatial distribution of occupation, and, in combination with other magnetic properties [e.g. anhysteretic remanent magnetization (ARM) and saturation isothermal remanent magnetization (SIRM)], it is possible to infer the intensity of habitation or to determine the provenance of archaeological materials (Thompson and Oldfield 1986; Dearing 1994).

\subsubsection{Acoustic Procedures}

Acoustic measurements are undertaken by creating repeatable acoustical waves that enter the ground and are refracted or reflected by changes in density before returning to a series of geophones (Fig. 14.11). The study of the arrival times, amplitude and form of the returned wavefronts provides information about the stratigraphy of the subsurface and the presence of archaeological material.

The most common acoustic techniques in archaeological research are seismic reflection and bathymetry, particularly for the reconstruction of underwater palaeolandscapes (i.e. Tizzard et al. 2015). The acoustic response of subsurface sediments measured by seismic reflection provides two- and three-dimensional representations of the geometry of sedimentary depositional units, their internal structures and their lithology. Seismic methods are particularly suited to aquatic surveys, as the acoustic properties of water allow the geophones to be used without direct coupling to 
the seafloor which greatly enhances survey speed compared to terrestrial surveys.

On land, seismic methods are useful for geoarchaeological investigations as their relatively deep depth of penetration is well suited to mapping large monumental structures and mounds or reconstructing the palaeotopography. Seismic refraction is particularly useful for determining the depth to bedrock within archaeological sites (Fig. 14.12). In contrast, seismic reflection is very valuable in terrestrial archaeology to map site stratigraphy, with surface wave techniques in particular showing great potential for wider use.

\subsubsection{Other Geophysical and Geochemical Techniques}

Microgravity measurements are carried out using sensitive devices that measure small variations in the Earth's gravitational field. These alterations are usually caused by air-filled voids in the subsurface (e.g. tunnels, cavities, caves and architectural features; see Fig. 14.13). They show a significant contrast between mass density and the surrounding loose sediments or the parent rock.
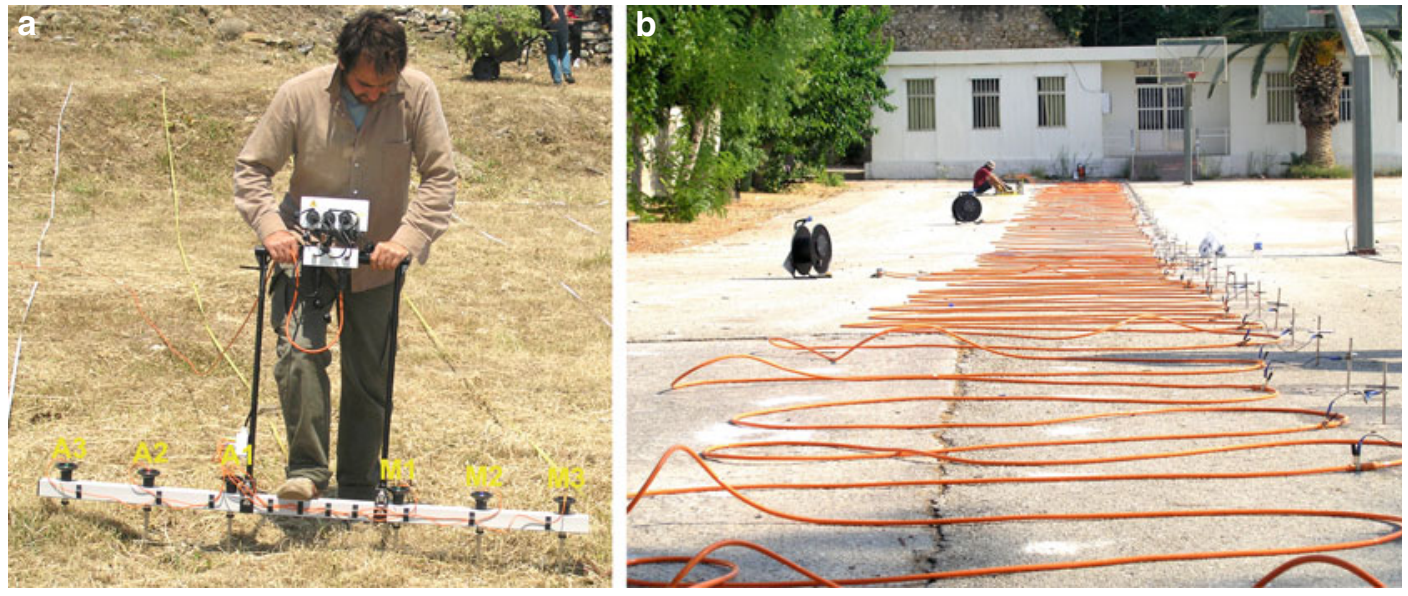

C

Depth Iteration 5 RMS error $=25.9 \%$

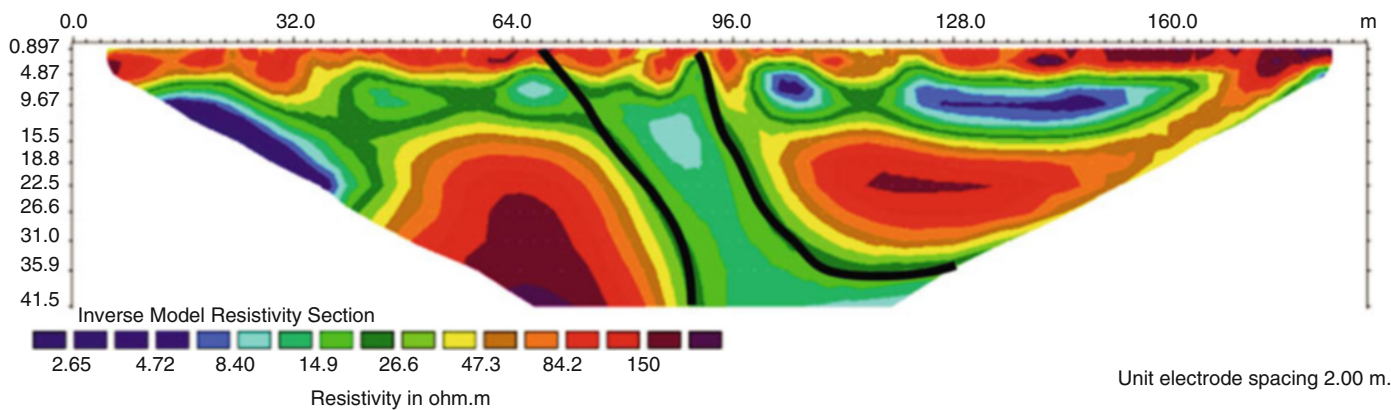

Fig. 14.9 (a) Geoscan Research Resistance meter (RM15) with multiplexer employing six electrodes (current electrodes As and potential electrodes Ms) at various configurations. (b) ERT extension of electrodes being used to map the area of the old Franciscan monastery of Rethymno (Mikrasiaton plaza) in Crete. (c) Stratigraphic results of an ERT transect measured above a fault (see the black line) within the suggested ancient port of
Priniatikos Pyrgos at Istron, Crete (Sarris et al. 2014). (d) $2 \mathrm{D}$ representation of the $3 \mathrm{D}$ resistivity model shown as horizontal slices with increasing depth in the area of Mikrasiaton Square at the centre of the old town of Rethymno in Crete. The architectural relics of a Franciscan monastery become obvious towards the southern part of the surveyed area (Papadopoulos et al. 2008) 


\section{D RESISTIVITY MODEL}

d
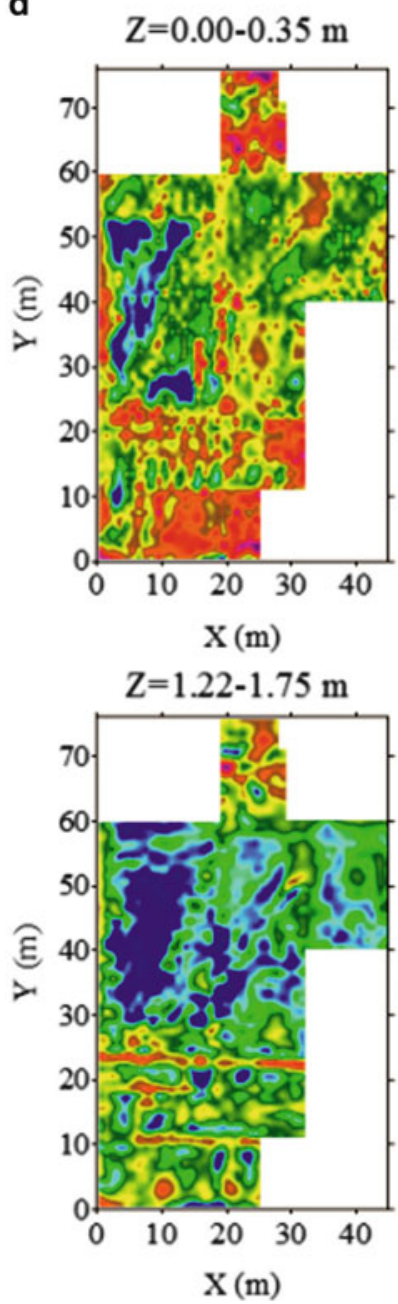

5 Iterations, $\mathrm{RMS}=9.94 \%$
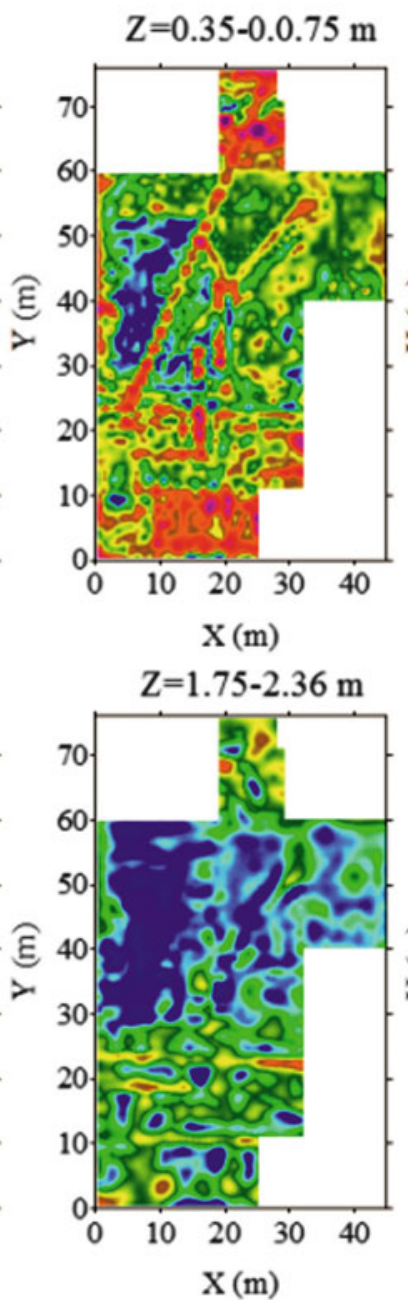
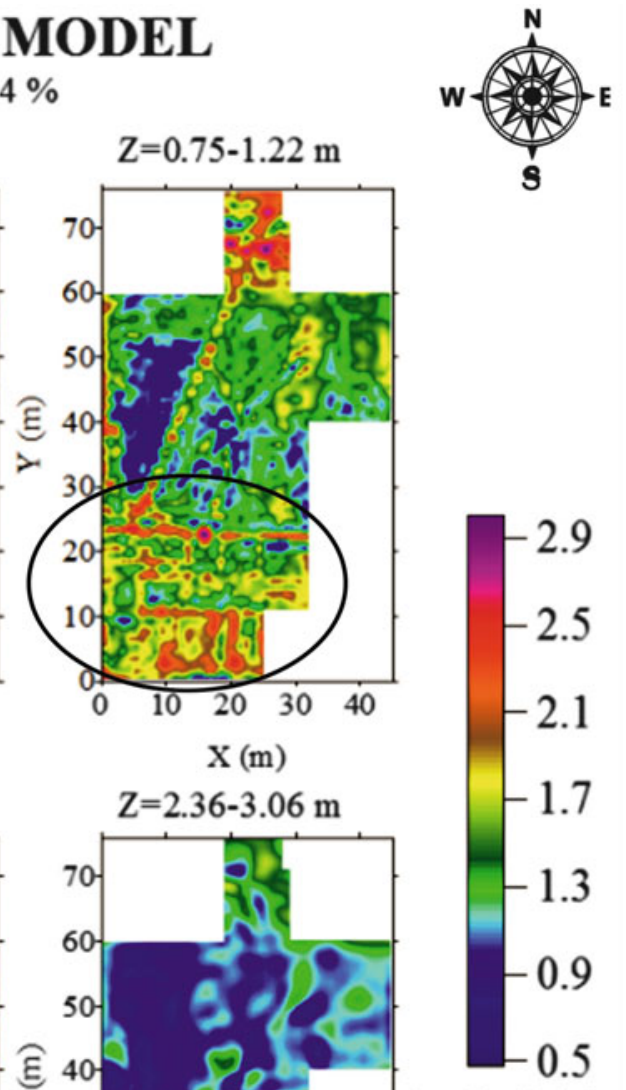

$\log$ Resistivity Ohm-m

Fig. 14.9 (continued)

Gamma spectroscopy is another geophysical approach that measures the gamma rays emitted by radioactive materials. It has been widely used by soil scientists to map soil types through plotting ternary diagrams of K-Th-U concentration. Mapping soils with gamma spectroscopy is very effective, because the radiometric footprint of a soil reflects both the mineralogy of the parent rock and the effect of weathering. Even though this technique has not been widely used in archaeology, it qualifies well for validating soil mapping results obtained by complementary methods like electromagnetic induction.

Another approach is the mapping of novel and short-lived isotopes such as ${ }^{137} \mathrm{Cs}$ and ${ }^{241} \mathrm{Am}$, which were deposited by the fallout from nuclear testing and accidents. The method provides an alternative for mapping disturbance on the basis that these isotopes are deposited on the surface and chemically immobile. Given that isotopes are distributed throughout the whole soil profile rather than just on the surface, a mixing of the soil layers can be presumed. Both Cs and Am 
approaches have the potential to assist geoarchaeological investigation by providing information about the sedimentary matrix of the archaeological site and determining if it has recently been disturbed by anthropogenic or natural processes.

Quite similar to isotope mapping is the chemical analysis of soils, which may indicate anthropogenic activity including agricultural and workshop activities, animal husbandry, construction of ditches, etc. Phosphate analysis, trace element analysis $(\mathrm{Cu}, \mathrm{Mn}, \mathrm{Mo}, \mathrm{Ca}, \mathrm{Se}, \mathrm{Sr}, \mathrm{Zn}, \mathrm{Cd}, \mathrm{Cr}$, $\mathrm{Cu}, \mathrm{Ni}, \mathrm{Pb}$ ) and assessment of chemical stability of organic chemical compounds are the most widely used approaches contributing to the recognition of former land-use practices and past human occupation in general. Calorimetric measurements, atomic absorption spectrometry, inductively coupled plasma mass spectrometry and gas chromatography-mass spectrometry are usually employed (Szostek et al. 2005; Price and Burton 2012; Manhita et al. 2014; Lauer et al. 2014)

\subsection{Examples for Principal Applications}

Geophysical methods have a wide range of application within archaeology in general, but their explicit use for solving geoarchaeological questions is principally related to three major aspects: the determination of sediment stratigraphy, the mapping of soil disturbance related to human occupation and the reconstruction of palaeolandscapes.

Sediment Stratigraphy Understanding the stratigraphy of an archaeological site is crucial for effective excavation planning, palaeoenvironmental reconstruction and putting excavation results into context, particularly with regard to geochronology. Yet geophysical methods are mostly currently used to simply locate and map archaeological sites and not to determine key stratigraphic features. The most important information that can be obtained using geophysics includes depth to bedrock, thickness and lateral extent of stratigraphic features and the location of archaeological material with respect to the stratigraphy.

Depth to bedrock and geomorphology of the surface provide important information about past depositional conditions and are key for correctly locating archaeological excavations so as to resolve the most complete record of occupation. Besides GPR and ERT, which are the most suitable techniques for investigating the vertical stratigraphy of archaeological sites, on-site or downhole magnetic susceptibility measurements also provide promising results. When it comes to horizontal mapping, EMI, GPR, soil resistivity, ERT and gamma spectroscopy are particularly suitable.

\section{a}

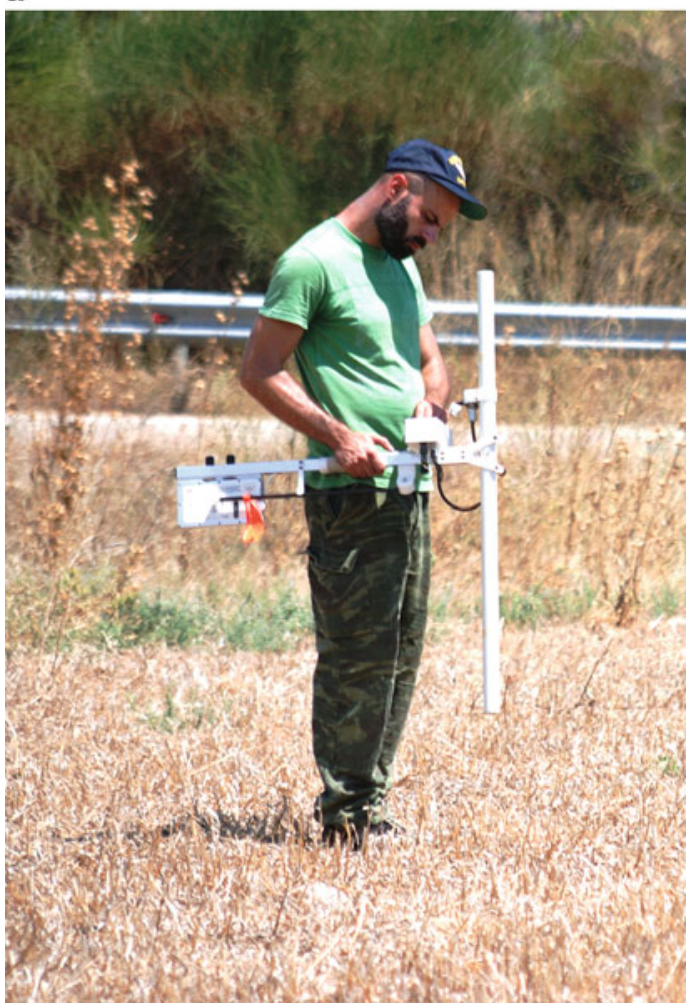

Fig. 14.10 (a) A single fluxgate gradiometer sensor of Bartington G601. (b) An eight-sensor fluxgate gradiometer array of SENSYS surveying the Neolithic tell of Perdika 2 at Central Greece. (c) Indicative results from the single sensor magnetic survey of the Agora of Sikyon in Peloponnese (Sarris et al. 2008). (d) Multisensory survey of Almyriotiki Neolithic tell at Central Greece. Results have been superimposed on a WorldView-2satellite image (2 June 2012) (Sarris et al. 2015a) 
b
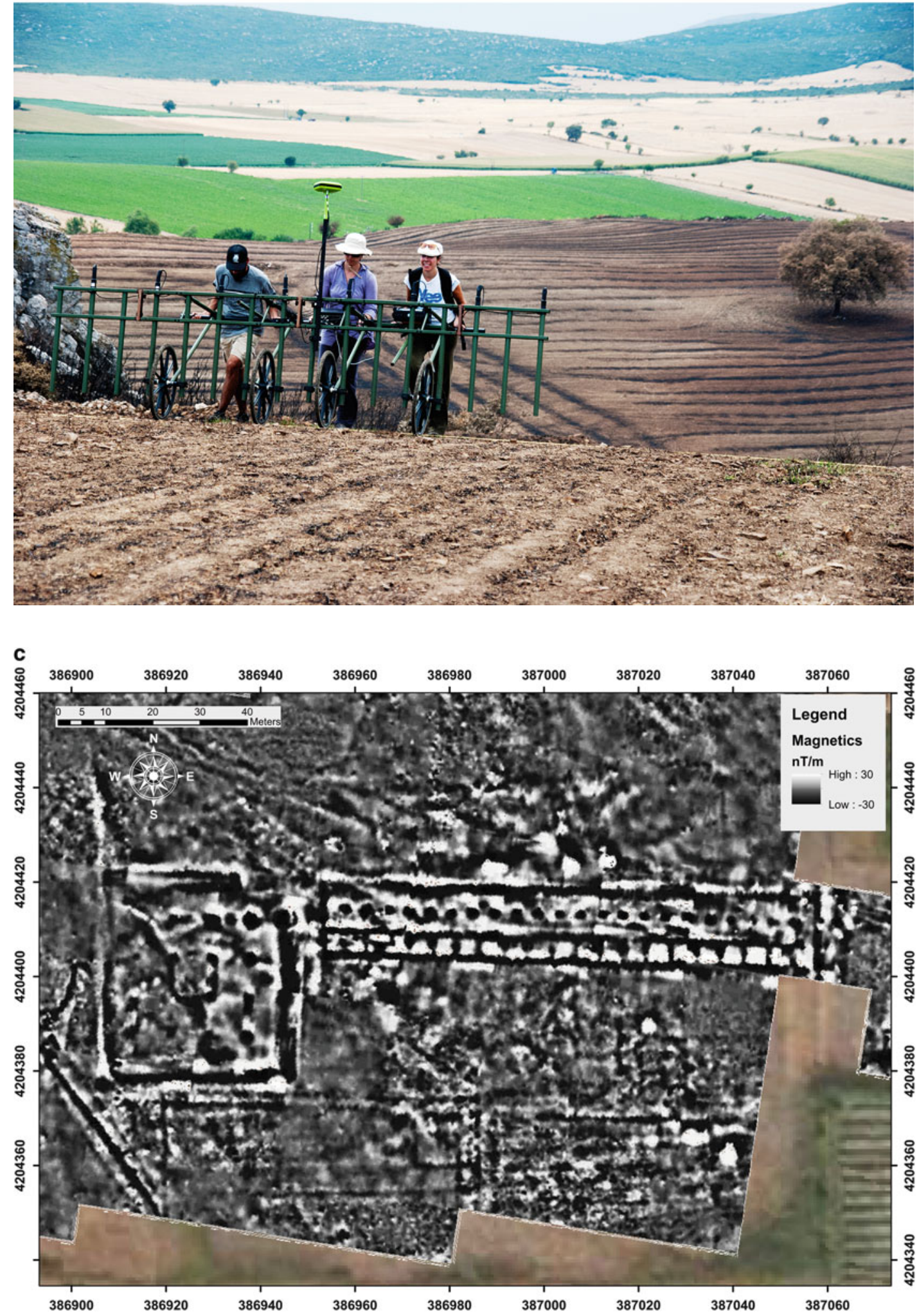

Fig. 14.10 (continued) 


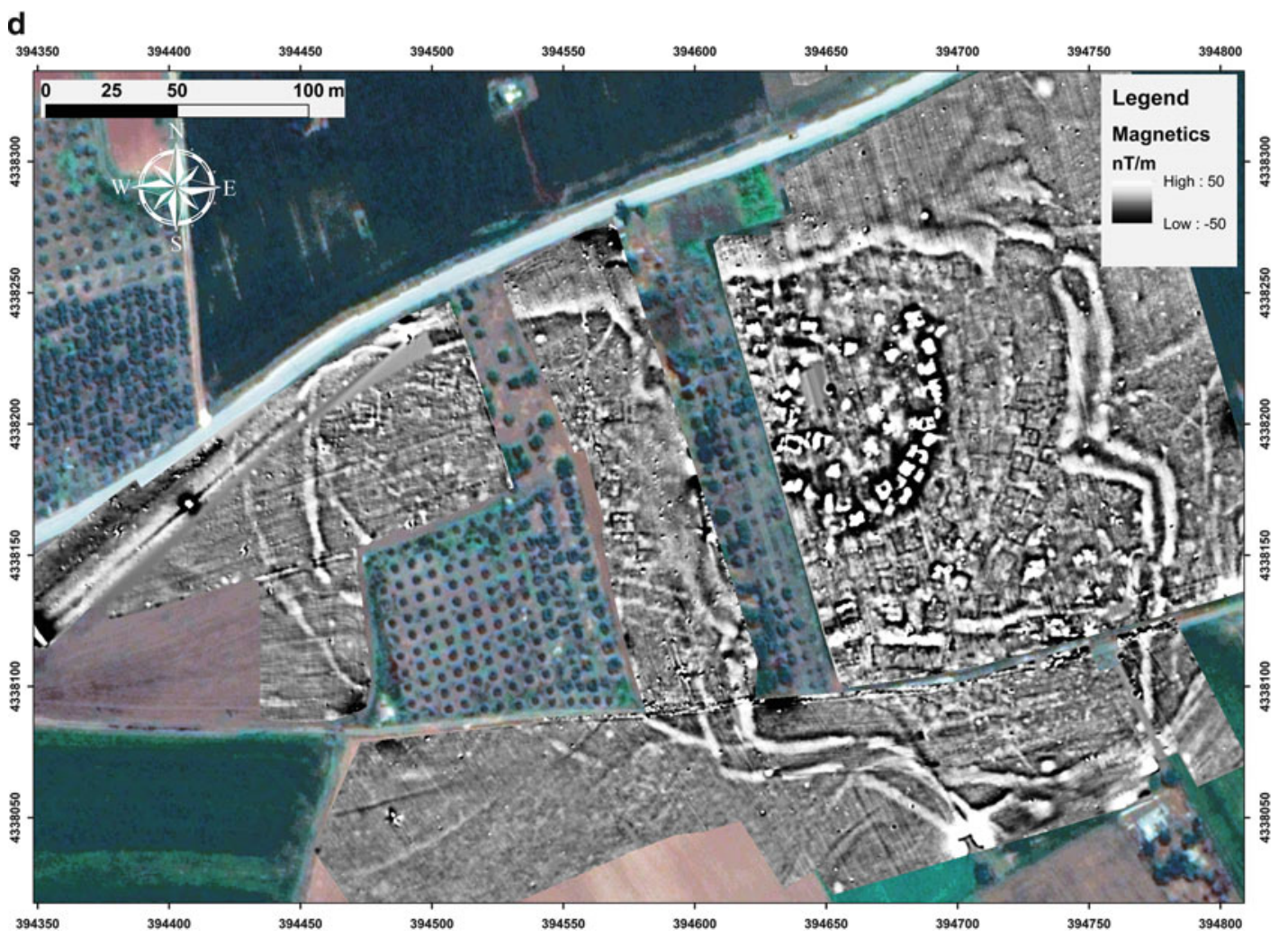

Fig. 14.10 (continued)

\section{Stratigraphic Disturbance of Sediments} and Soils Soil stratigraphy (i.e. the development of recognizable soil horizons) typically takes significant time to develop, and, as a result, its disturbance can provide crucial information about the historical record of an archaeological site. This perturbation can be mapped geophysically through a number of techniques. Among others, alteration of soil properties due to mixing of different components can be investigated by GPR, EMI, resistivity or gamma spectrometry, while changes of soil porosity are shown best by ERT and GPR. The latter approach is particularly appropriate for the detection of unmarked graves, as in the absence or following the decay of a coffin; soil perturbation caused by the dig is the most evident feature to be detected by geophysical methods (Moffat 2015; Conyers 2006).
Reconstruction of Palaeolandscapes Buried palaeolandscapes provide valuable information for the identification and the understanding of archaeological sites, particularly when surface features are absent. The reconstruction of palaeoenvironments allows an identification of areas with sediment accumulation (and, thus, prospective for preserving archaeological material) and areas characterized by landforms (such as rivers or shorelines) conducive to ancient land use. In addition, it can also provide information about past climatic conditions, which had an impact on human occupation history. Besides terrestrial palaeolandscape reconstructions, which are quite often based on multi-method approaches (e.g. by combining ERT, seismics, geochemical studies), aquatic palaeoenvironments that have been submerged due to 


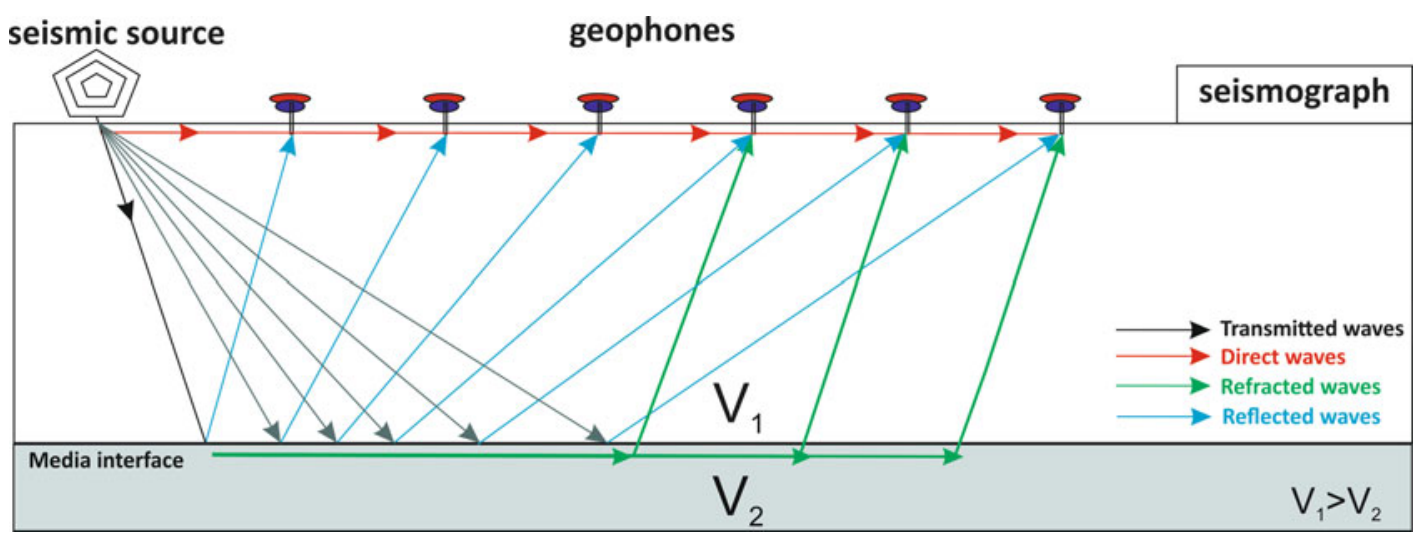

Fig. 14.11 Typical setup in a seismic survey. The seismic source is needed to generate controlled acoustical waves that are either reflected or refracted at the different media interfaces to be recorded by the geophones. Geophones convert the velocity of the registered waves into voltage

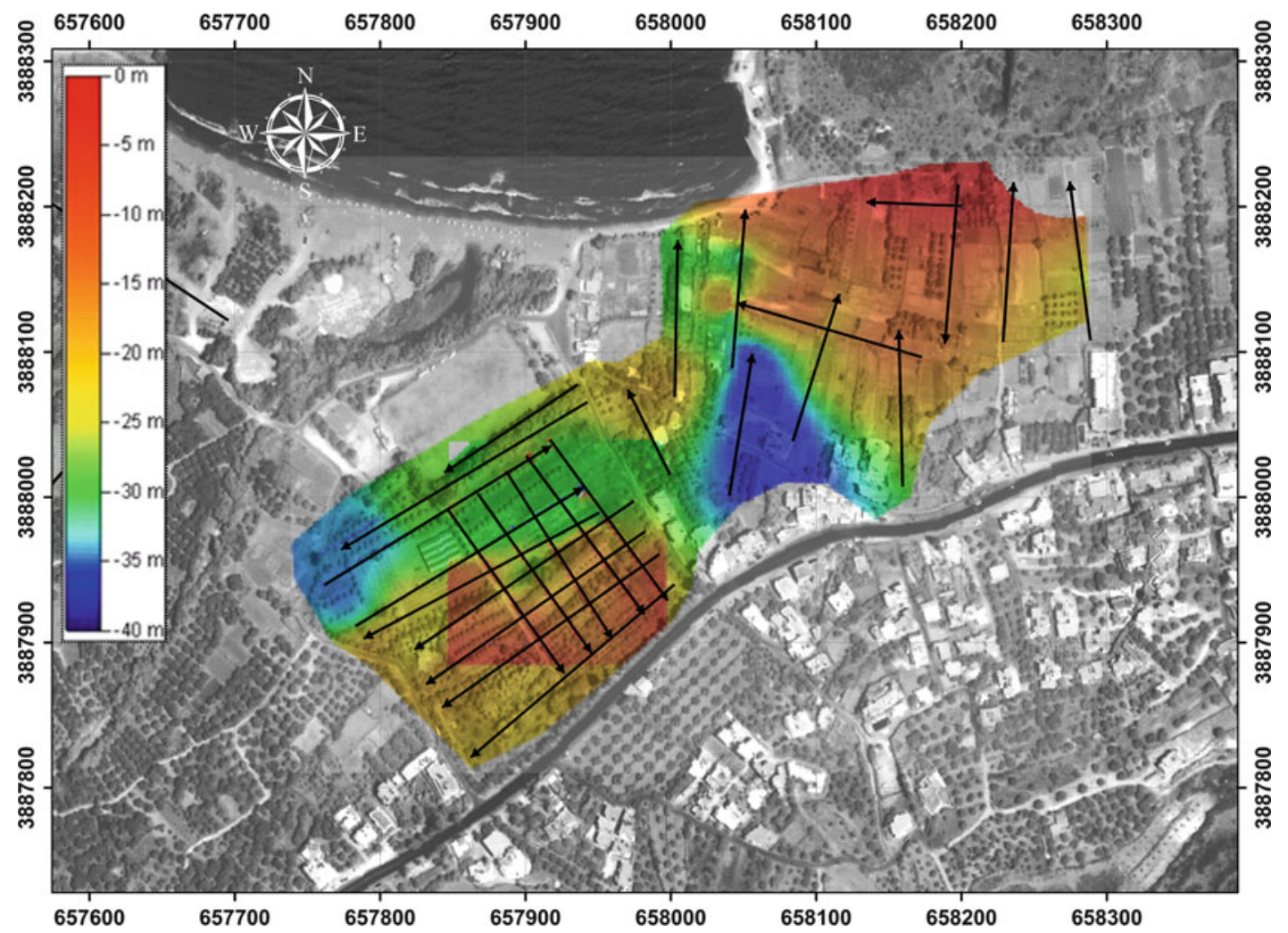

Fig. 14.12 Results of a seismic refraction survey at the area of Priniatikos Pyrgos (Istron, E. Crete, Greece), where an assumed ancient port has been hypothesized. The area has been completely covered by alluvial deposits and conglomerates as a result of past landslides and tectonic activity. The image represents the depth to the bedrock which reaches levels of about $40 \mathrm{~m}$ below surface, superimposed on a panchromatic Ikonos image (30 July 2001). The arrows represent the seismic transects along which the geophones were placed. The seismic results have also been verified through ERT measurements (Sarris et al. 2014) 


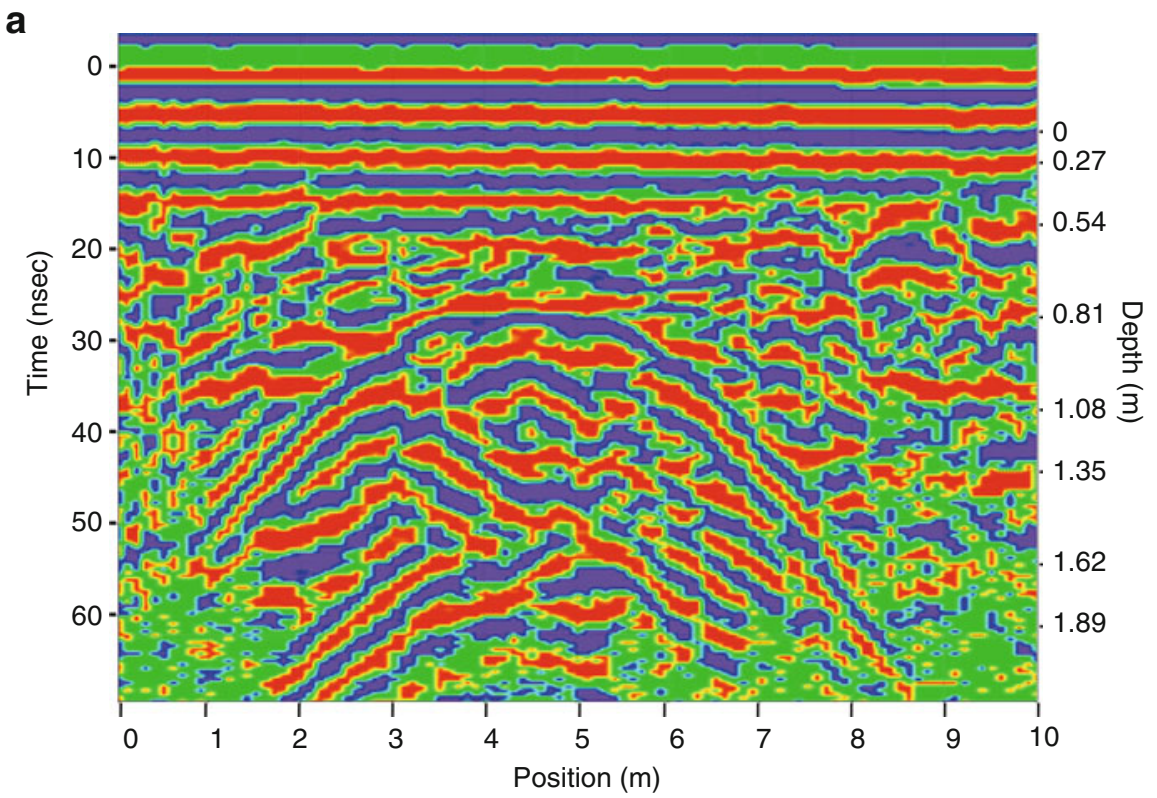

b GRAVITYPROFILE KEX1

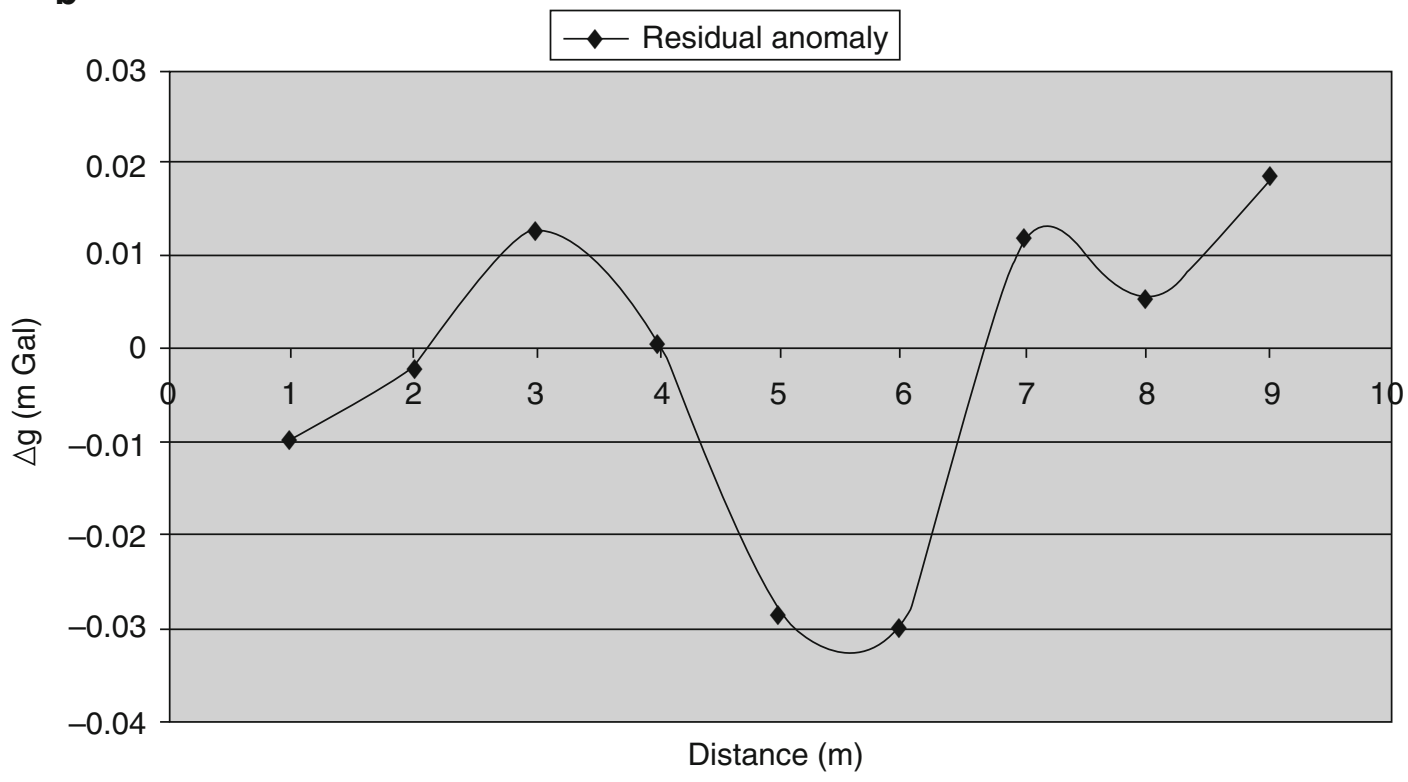

Fig. 14.13 (a) GPR radargram (taken with Noggin Plus GPR with $250 \mathrm{MHz}$ antenna) above a Roman chamber tomb at the Kenchreai cemetery located at Koutsonglia Ridge, north of the harbour of Kenchreai in NW Peloponnese. The tomb has a diameter of $3.55 \mathrm{~m}$ and an interior height of about $2.5 \mathrm{~m}$, located at a depth of 1.1 from the ground level. The amplitude of the GPR data is represented by red (positive reflection), blue (negative reflection) and green (minor dielectric constant differences between the media creating almost no reflective interfaces) colours. (b) Gravity residual anomalies recorded at the same transect using the Lacoste and Romberg model D land microgravitometer. The centre of the tomb chamber is located approximately at the middle of the transect (Sarris et al. 2007) 
Table 14.1 Strengths and weaknesses of geophysical methods in geoarchaeological surveys

\begin{tabular}{|c|c|c|}
\hline Method & Strengths & Weaknesses \\
\hline $\begin{array}{l}\text { Ground- } \\
\text { penetrating radar }\end{array}$ & $\begin{array}{l}\text { - Application in both shallow and medium depth } \\
\text { investigations } \\
\text { - Suitable for use in both rural and urban settings } \\
\text { - Operation in limnic environments } \\
\text { - Provision of high-resolution data } \\
\text { - Fast data acquisition } \\
\text { - Provision of stratigraphy and volumetric images of } \\
\text { the subsurface } \\
\text { - Ability to map geological and/or geomorphologic } \\
\text { features } \\
\text { - Determination of the depth to bedrock } \\
\text { - Ability to detect voids, caves, tombs, wall } \\
\text { structures }\end{array}$ & $\begin{array}{l}\text { - Need of good contact with ground surface } \\
\text { - Dependence on climatic conditions } \\
\text { - Not possible to operate in marine } \\
\text { investigations } \\
\text { - Specialized way of data processing } \\
\text { - Shielded antennas are required for } \\
\text { surveying inside structures } \\
\text { - Medium mobility and flexibility of } \\
\text { instrumentation }\end{array}$ \\
\hline $\begin{array}{l}\text { Electromagnetic } \\
\text { induction } \\
\text { methods }\end{array}$ & $\begin{array}{l}\text { - Application in both shallow and deep } \\
\text { investigations } \\
\text { - Suitable for use in rural settings } \\
\text { - No need of contact with ground } \\
\text { - Ideal for large-scale surveys } \\
\text { - Large mobility of instrumentation } \\
\text { - Provision of both soil conductivity and soil } \\
\text { magnetic susceptibility } \\
\text { - Provision of information about geology and } \\
\text { lithology, stratigraphic changes and the depositional } \\
\text { record of a landscape } \\
\text { - Ability to detect ditches, pits, burnt architecture, } \\
\text { palaeosoils, palaeochannels which may accumulate } \\
\text { magnetic minerals through pedogenic or erosional } \\
\text { processes (French 2003) }\end{array}$ & $\begin{array}{l}\text { - Not suitable in urban environments } \\
\text { - Easy to medium degree of data processing } \\
\text { - Difficult to collect multi-sensor data as an } \\
\text { array }\end{array}$ \\
\hline $\begin{array}{l}\text { Electrical } \\
\text { resistance } \\
\text { techniques }\end{array}$ & $\begin{array}{l}\text { - Application in medium depth and deep } \\
\text { investigations } \\
\text { - Suitable for use in both rural and urban settings, } \\
\text { limnic and sea investigations } \\
\text { - Easy processing of the data } \\
\text { - 2D and 3D modelling of the subsurface geological } \\
\text { strata } \\
\text { - Straightforward application in archaeological } \\
\text { surveys } \\
\text { - Ideal for the detection of deep depositional targets } \\
\text { (e.g. ancient ports covered by alluvial deposits, } \\
\text { ditches and palaeochannels) }\end{array}$ & $\begin{array}{l}\text { - Need of contact with ground surface } \\
\text { - Dependence on climatic conditions } \\
\text { - ERT measurements need specialized data } \\
\text { treatment } \\
\text { - Expensive ERT instrumentation } \\
\text { - ERT is relative bulky and slow for } \\
\text { extensive mapping } \\
\text { - Medium to hard mobility and flexibility of } \\
\text { instrumentation }\end{array}$ \\
\hline $\begin{array}{l}\text { Magnetic } \\
\text { methods }\end{array}$ & $\begin{array}{l}\text { - Application in shallow depth investigations } \\
\text { - Suitable for use in rural settings } \\
\text { - No need of contact with ground } \\
\text { - Ideal for extensive mapping surveys with high } \\
\text { sampling resolution } \\
\text { - Easy processing of the data } \\
\text { - Large mobility of instrumentation } \\
\text { - Detection of ferrous or burnt features, metal } \\
\text { objects } \\
\text { - Mapping the extent of pedogenic soil minerals }\end{array}$ & $\begin{array}{l}\text { - Not suitable in urban environments } \\
\text { - Dependence on terrain conditions } \\
\text { - Very sensitive to metallic objects } \\
\text { - Not appropriate for sediment stratigraphy } \\
\text { studies }\end{array}$ \\
\hline $\begin{array}{l}\text { Magnetic } \\
\text { susceptibility } \\
\text { methods }\end{array}$ & $\begin{array}{l}\text { - Application in shallow depth investigations } \\
\text { - Suitable for use in rural settings } \\
\text { - Ability to map the depositional conditions at } \\
\text { archaeological sites and the occupation layers } \\
\text { - Detection of extension and intensity of occupation } \\
\text { - Provenance of archaeological materials } \\
\text { - Proxy for the success of the magnetic survey }\end{array}$ & $\begin{array}{l}\text { - Not suitable in urban environments } \\
\text { - Need for Laboratory measurements } \\
\text { - Not appropriate for high resolution or } \\
\text { extensive surveys }\end{array}$ \\
\hline
\end{tabular}


Table 14.1 (continued)

\begin{tabular}{|c|c|c|}
\hline Method & Strengths & Weaknesses \\
\hline $\begin{array}{l}\text { Acoustic } \\
\text { procedures }\end{array}$ & $\begin{array}{l}\text { - Application in medium depth and deep } \\
\text { investigations } \\
\text { - Suitable for use in both rural and urban settings, } \\
\text { limnic and sea investigations } \\
\text { - Ability to map the sediment stratigraphy and } \\
\text { reconstruct the palaeotopography and the depth to } \\
\text { bedrock } \\
\text { - Ability to map large monumental structures and } \\
\text { mounds }\end{array}$ & $\begin{array}{l}\text { - Need of good contact with ground surface } \\
\text { - Specialized way of data processing } \\
\text { - Slow method for mapping surveys } \\
\text { - Medium to hard mobility and flexibility of } \\
\text { instrumentation } \\
\text { - Expensive instrumentation }\end{array}$ \\
\hline Microgravity & $\begin{array}{l}\text { - Application in shallow and medium depth } \\
\text { investigations } \\
\text { - Ideal for detection of voids, caves and monumental } \\
\text { structures }\end{array}$ & $\begin{array}{l}\text { - Very expensive instrumentation } \\
\text { - Not suitable in urban environments } \\
\text { - Tedious data processing } \\
\text { - Not appropriate for extensive mapping }\end{array}$ \\
\hline $\begin{array}{l}\text { Chemical } \\
\text { analysis }\end{array}$ & $\begin{array}{l}\text { - Provision of information regarding agricultural } \\
\text { and workshop activities, animal husbandry, } \\
\text { construction of ditches } \\
\text { - Reconstruction of past land-use practices }\end{array}$ & $\begin{array}{l}\text { - Need for Laboratory measurements } \\
\text { - Not appropriate for high resolution or } \\
\text { extensive surveys }\end{array}$ \\
\hline $\begin{array}{l}\text { Gamma } \\
\text { spectroscopy }\end{array}$ & $\begin{array}{l}\text { - Fast survey } \\
\text { - Ability to map soil types } \\
\text { - Appropriate for sediment stratigraphy studies }\end{array}$ & - Sensitivity and reliability issues \\
\hline $\begin{array}{l}\text { Aerial and } \\
\text { satellite remote } \\
\text { sensing }\end{array}$ & $\begin{array}{l}\text { - Provision of multispectral information } \\
\text { - Provision of a digital terrain model (DEM) } \\
\text { - Ideal for regional landscape studies }\end{array}$ & $\begin{array}{l}\text { - Limitation to shallow depth investigations } \\
\text { - Dependence of the time of imagery, crop } \\
\text { growth, spatial resolution of the satellite } \\
\text { platform } \\
\text { - Specialized software for data processing }\end{array}$ \\
\hline
\end{tabular}

a

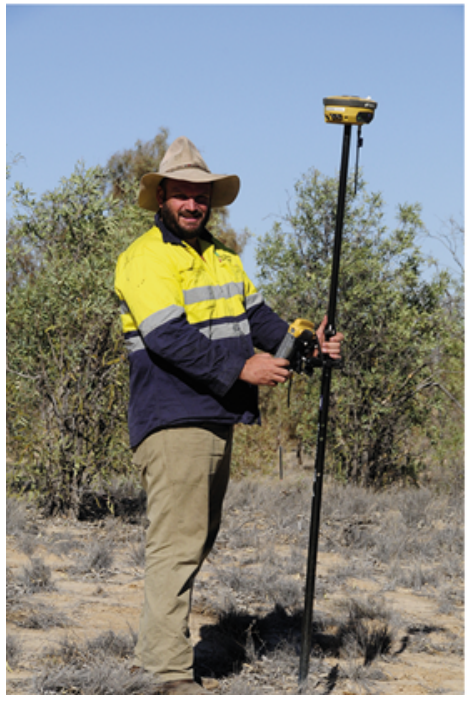

b

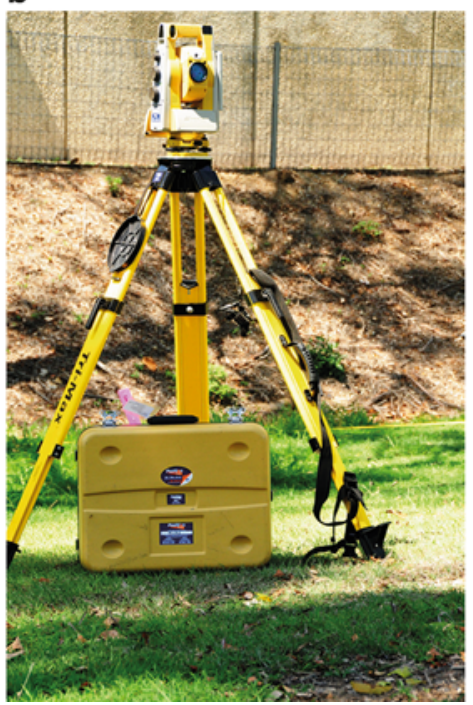

C

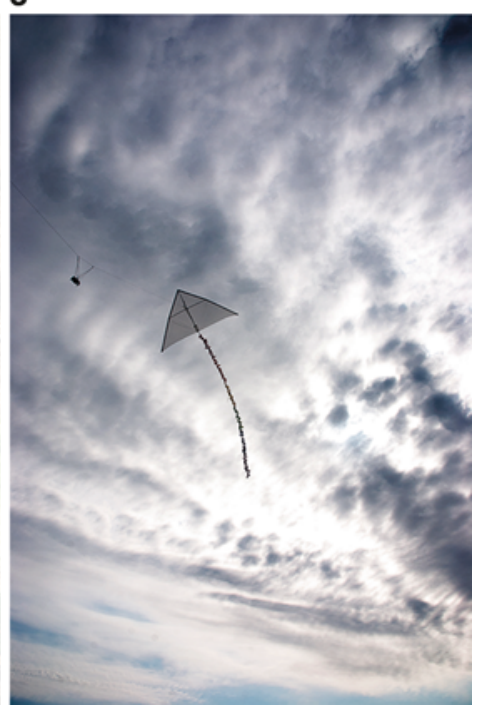

Fig. 14.14 (a) Differential GPS being used to survey an archaeological site in NE South Australia. (b) Robotic total station being used for mapping a cemetery in Queensland, Australia. (c) Camera attached to a kite for acquiring aerial photos from the Neolithic site of Perdika 2 at Thessaly, Central Greece. (d) Satellite image of the urban plan of the ancient city of Ferai (Central Greece); pansharpened IHS transformation of the 15 June 2009 Quickbird image showing linear features associated with roads to the northern fields. (e) Same image as in (d); modified simple ratio (MSR) transformation of the 4 May 2010 GeoEye-1 image indicating the projection of the above features to the southern field (Sarris et al. 2015b) 

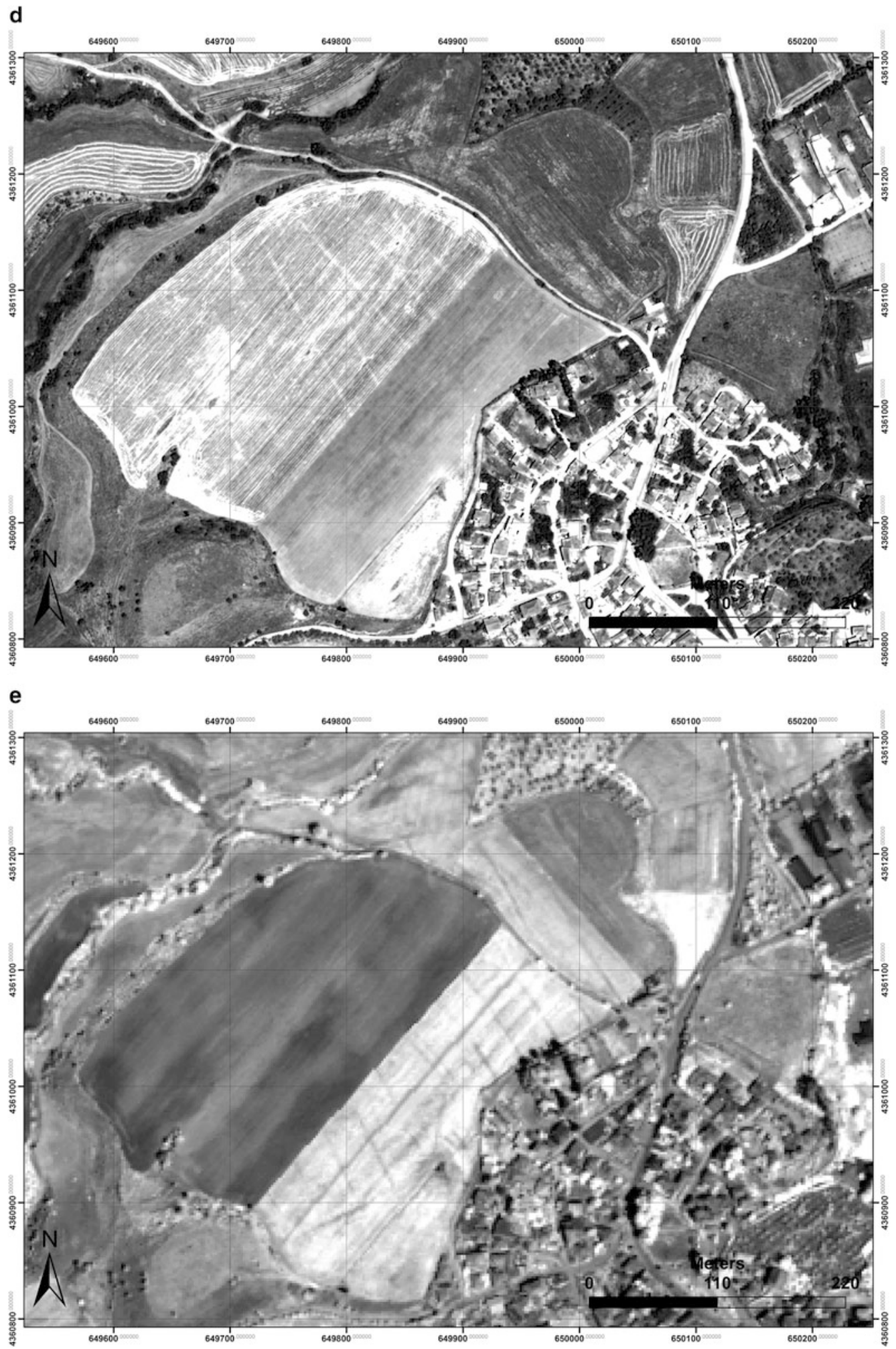

Fig. 14.14 (continued) 
sea level rise are primarily investigated by acoustic methods (Tizzard et al. 2015).

\subsection{Final Remarks}

Geophysical techniques can make a significant contribution to geoarchaeological investigations. They allow non-invasive and rapid imaging of archaeological landscapes and help answer scientific questions by considering a site integrally along with its environmental surroundings. The methodological spectrum includes the investigation of the site stratigraphy, the mapping of remnants of past human occupation and the reconstruction of palaeolandscapes. Each method has its own merits and limitations, and it is through the combination of the various techniques that various aspects of the archaeolandscapes can be addressed (Sarris, 2013, 2015) (Table 14.1).

It has to be noted though that geophysical prospection techniques cannot and shall not independently address all questions arising from the archaeological research. Moreover, they are usually combined with other applications spanning from topographic mapping and geomorphometry of the landscape using LiDAR, DGPS units, robotic total stations and $3 \mathrm{D}$ laser scanners to aerial reconnaissance and satellite remote sensing (Fig. 14.14). Only the integration of the above-mentioned techniques with on-site excavations can provide a more holistic approach to the questions related to the interaction between human occupation and landscapes.

Acknowledgments This work was carried out under the project "ARCHERS: Advancing Young Researchers' Human Capital in Cutting Edge Technologies in the Preservation of Cultural Heritage and the Tackling of Societal Challenges" which is funded by an exclusive donation of the Stavros Niarchos Foundation ("Stavros Niarchos Foundation-FORTH Fellowships").

\section{References}

Annan AP (2009) Chapter 1 - Electromagnetic principles of ground penetrating radar. In: Jol HM (ed) Ground penetrating radar theory and applications. Elsevier, Amsterdam, pp 1-40

Armstrong KL, Kalayci T (2015) Images of the past: magnetic prospection in archaeology. In: Sarris A (ed) Best practices of geoinformatic technologies for the mapping of archaeolandscapes. Archaeopress Publishing, Oxford, pp 1-12

Aspinall A, Gaffney C, Schmidt A (2008) Magnetometry for archaeologists. AltaMira Press, Lanham

Conyers LB (2006) Ground-penetrating radar techniques to discover and map historic graves. Hist Archaeol 40 (3):64-73

Conyers LB (2013) Ground-penetrating radar for archaeology. AltaMira Press, Lanham

Conyers LB (2015a) Analysis and interpretation of GPR datasets for integrated archaeological mapping. Near Surf Geophy 23(6):645-651

Conyers LB (2015b) Ground-penetrating radar for geoarchaeology. Wiley, London

Dalan RA (2007) A review of the role of magnetic susceptibility in archaeogeophysical studies in the USA: recent developments and prospects. Archaeol Prospect 15(1):1-31

Dalan RA, Banerjee SK (1998) Solving archaeological problems using techniques of soil magnetism. Geoarchaeology 13(1):3-36

Dearing J (1994) Environmental magnetic susceptibility. Using the Bartington MS2 system. Chi Publications, Kenilworth

French C (2003) Geoarchaeology in action. Studies in soil micromorphology and landscape evolution. Routledge, London

Jol H (1995) Ground penetrating radar antennae frequencies and transmitter powers compared for penetration depth, resolution and reflection continuity. Geophys Prospect 43(5):693-709

Hecht S, Fassbinder J (2006) Der Blick in den Untergrund: Magnetometrie und Geoelektrische Tomographie. Geoarchäologie. Geogr Rundsch 58(4): $38-45$

Laigre L, Reynards E, Arnaud-Fassetta G, Baron L, Glenz D (2012) Characterisation of the Rhône river palaeodynamics in Central Valais (Switzerland) with the electrical resistivity tomography method. Géomorphol Relief Processus Environ 4:405-426

Lauer F, Prost K, Gerlach R, Pätzold S, Wolf M, Urmersbach S, Lehndorff E, Eckmeier E, Amelung W (2014) Organic fertilization and sufficient nutrient status in prehistoric agriculture? - Indications from multi-proxy analyses of archaeological topsoil relicts. Plos One. open access

Linford N, Linford P, Martin L, Payne A (2010) Stepped frequency ground-penetrating radar survey with a multi-element array antenna: results from field application on archaeological sites. Archaeol Prospect 17:187-198

Loke MH (2000) Electrical imaging surveys for environmental and engineering studies. A practical guide to 2-D and 3-D surveys. http://www.geo.mtu.edu/ $\sim$ ctyoung/LOKENOTE.PDF 
Manataki M, Sarris A, Donati JM, Garcia CC, Kalayci T (2015) GPR: theory and practice in archaeological prospection. In: Sarris A (ed) Best practices of geoinformatic technologies for the mapping of archaeolandscapes. Archaeopress Publishing, Oxford, pp 13-24

Manhita A, Martins S, Costa J, Prazeres C, Rocha L, Dias C, Mirão J, Teixeira D (2014) A multi-analytical approach for the study of Neolithic pottery from the Great Dolmen of Zambujeiro (Évora, Portugal) - a preliminary study. e-Conserv J 2:66-78

Merz K, Green AG, Buchli T, Springman SM, Maurer H (2015) A new 3-D thin-skinned rock glacier model based on helicopter GPR results from the Swiss Alps. Geophys Res Lett 42:4464-4472

Moffat I (2015) Locating graves with geophysics. In: Sarris A (ed) Best practices of geoinformatic technologies for the mapping of archaeolandscapes. Archaeopress Publishing, Oxford, pp 45-53

Papadopoulos NG, Sarris A, Giapitsoglou C (2008) Mapping the buried archaeological remains in the area of the old Turkish school of Rethymno (Crete, Greece) through the application of surface ERT \& GPR techniques. In: Zacharias N, Georgakopoulou M, Polykreti K, Fakorellis G, Vakouli T (eds) Proceedings of the 5th symposium of the Greek archaeometry society. Papazisis, Athens, pp 101-116

Papadopoulos N, Sarris A, Yi MJ, Kim JH (2009) Urban archaeological investigations using surface 3D ground penetrating and electrical resistivity tomography methods, joint issue of the Australian Society of Exploration Geophysicists, the Korean Society of Exploration Geophysicists and the Society of Exploration Geophysicists of Japan. Explor Geophys 40:56-68

Price D, Burton J (2012) An introduction to archaeological chemistry. Springer, New York

Sarris A (ed) (2015) Best practices of geoinformatic technologies for the mapping of archaeolandscapes. Archaeopress Archaeology: Archaeopress Publishing, Oxford

Sarris A (2013) Multi+ or manifold geophysical prospection?. In: Earl G, Sly T, Chrysanthi A, Murrieta-Flores P, Papadopoulos C, Romanowska I, Wheatley D (eds) Archaeology in the Digital Era Volume II, e-Papers from the 40th Conference on computer applications and quantitative methods in archaeology (CAA2012), Amsterdam University Press, Amsterdam, p 761-770

Sarris A, Papadopoulos N (2012) Geophysical Surveying in Urban Centers of Greece. In: Boner W, Uhlirz S, Dollhofer L (eds) Proceedings of the 16th international congress on cultural heritage and new technologies, Museen der Stadt Wien Stadtarchaologie, pp 96-114

Sarris A, Kalayci T, Simon FX, Donati J, Garcia CC, Manataki M, Cantoro G, Kalogiropoulou E, Karampatsou G, Argyriou N, Dederix S, Manzetti C,
Nikas N, Vouzaxakis K, Rondiri V, Arachoviti P, Almatzi K, Efstathiou D, Stamelou E (2015b) Opening a new frontier in the Neolithic settlement patterns of Eastern Thessaly, Greece. International conference on communities, landscapes, and interaction in Neolithic Greece, Institute for Mediterranean Studies-FORTH, Rethymno. http://igean.ims.forth.gr/sites/default/files/ publications/wSarris_et\%20al_Neolithic_Greece_2015. pdf

Sarris A, Donati J, Kalayci T, Simon FX, Manataki M, Garcia C, Cantoro G (2015a) Amalgamation of satellite remote sensing and geophysical prospection for the investigation of ancient cities: two case studies from Demetrias and Pherai at the region of Magnesia, Thessaly, Central Greece, 8th Congress of Balkan Geophysical Society in Chania, Crete, Greece. http:// politeia.ims.forth.gr/files/wmSarris_et_al_Balkan_2015. pdf

Sarris A, Papadopoulos N, Soupios S (2014) Contribution of geophysical approaches to the study of Priniatikos Pyrgos. In: Molloy BPC, Duckworth CN (eds) A cretan landscape through time: Priniatikos Pyrgos and environs, BAR International Series, vol 2634. Archaeopress, Oxford, pp 61-69

Sarris A, Papadopoulos N, Trigkas V, Kokkinou E, Alexakis D, Kakoulaki G, De Marco E, Seferou E, Shen G, Karaoulis M, Simirdanis K, Kondili F, Katifori M, Dogan M, Lolos Y, Kalpaxis T (2008) Recovering the urban network of ancient Sikyon through multi-component geophysical approaches. In: Posluschny A, Lambers K, Herzog I (eds) Layers of perception. Proceedings of the 35th international conference on computer applications and quantitative methods in archaeology (CAA), Berlin, Germany, 2-6 April, 2007. Kolloquien zur Vor- und Frühgeschichte 10:11-16

Sarris A, Dunn RK, Rife JL, Papadopoulos N, Kokkinou E, Mundigler C (2007) Geological and Geophysical Investigations in the Roman Cemetery at Kenchreai (Korinthia), Greece. J Archaeol Prospect 14:1-23

Scapozza C, Laigre L (2014) The contribution of electrical resistivity tomography (ERT) in Alpine dynamics geomorphology: case studies from the Swiss Alps. Géomorphol Relief Processus Environ 20(1):27-42

Schmidt A (2013) Earth resistance for archaeologists. AltaMira Press, Lanham

Simon FX, Moffat I (2015) Identification of shapes and uses of past landscapes through EMI survey. In: Sarris A (ed) Best practices of geoinformatic technologies for the mapping of archaeolandscapes. Archaeopress Publishing, Oxford, pp 25-34

Simon FX, Sarris A, Thiesson J, Tabbagh A (2015a) Mapping of quadrature magnetic susceptibility/magnetic viscosity of soils by using multi-frequency EMI. J Appl Geophys 120:36-47

Simon FX, Tabbach A, Sarris A (2015b) Practical assessment of a multi-frequency slingram EMI for archaeological prospection. In: Giligny $F$, Djindjian F, Costa L, Moscati P, Robert S (eds) Proceedings of 
the 42nd annual conference on CAA, CAA2014: 21st century archaeology- concepts, methods and tools, Archaeopress Archaeology, Oxford, p 43-49

Simyrdanis K, Papadopoulos N, Kim JH, Tsourlos P, Moffat I (2015) Archaeological investigations in the shallow seawater environment with electrical resistivity tomography. Near Surf Geophys 13:601-611

Szostek K, Głąb H, Lorkiewicz W, Grygiel R, Bogucki P (2005) The diet and social paleostratigraphy of Neolithic agricultural population of the Lengyel culture from Osłonki (Poland). Przegląd Antropologiczny Anthropol Rev 68:29-41

Thompson R, Oldfield F (1986) Environmental magnetism. Springer, Netherlands
Tizzard L, Bicket A, De Loecker D (eds) (2015) Seabed prehistory: investigating the palaeogeography and early middle Palaeolithic archaeology in the Southern North Sea. Oxbow Books, Oxford

Tonkov N (2014) Geophysical survey at the early Neolithic site of Yabalkovo. In: Roodenberg J, Leshtakov K, Petrova V (eds) Yabalkovo vol 1, ATE- Ars et Technica Expicatus, Sofia Univeristy "St. Kliment Ohridski", Sofia, pp 73-78

Trinks I, Johansson B, Gustafsson J, Emilsson J, Friborg J, Gustafsson C, Nissen J, Hinterleitner A (2010) Efficient, large-scale archaeological prospection using a true three-dimensional ground-penetrating radar array system. Archaeol Prospect 17:175-186

Open Access This chapter is licensed under the terms of the Creative Commons Attribution 4.0 International License (http://creativecommons.org/licenses/by/4.0/), which permits use, sharing, adaptation, distribution and reproduction in any medium or format, as long as you give appropriate credit to the original author(s) and the source, provide a link to the Creative Commons license and indicate if changes were made.

The images or other third party material in this chapter are included in the chapter's Creative Commons license, unless indicated otherwise in a credit line to the material. If material is not included in the chapter's Creative Commons license and your intended use is not permitted by statutory regulation or exceeds the permitted use, you will need to obtain permission directly from the copyright holder.

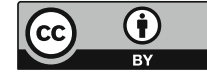

